\title{
إدارة المياه ودورها في التنمية الزراعية المستدامة في محافظة الأببار
}

\section{د ـ آمنة جبار مطر درويش الاليمي

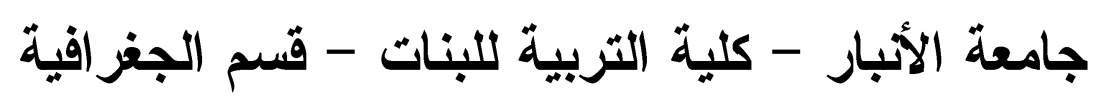

الخلاصة :

تسود العر اق ظروف مناخية جافة وشبه جافة، فضلاً عن معدلات التبخر العالية وكميات

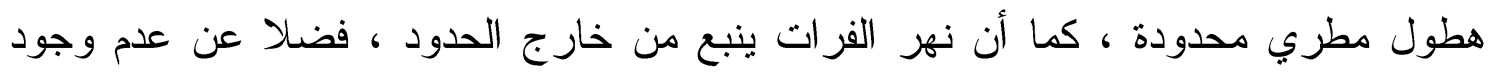

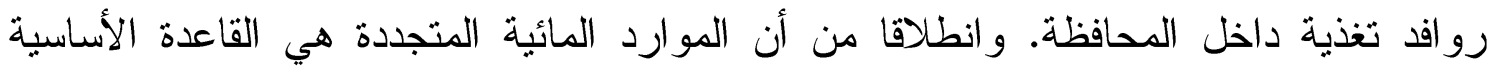

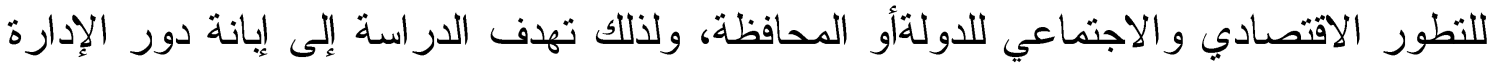

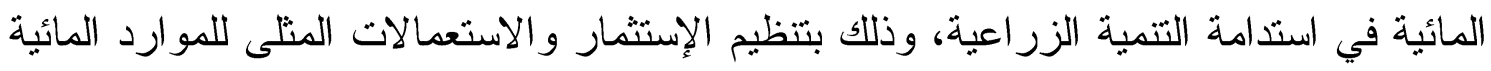

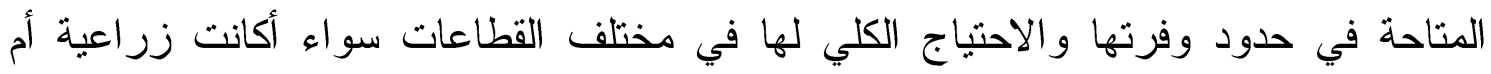
صناعية أم منزلية، في ضو ضو اتباع إدارة مائية تعتمد الأسس العلمية التي تسهم في تحقيق التنمية الزر اعية المستدامة قي المحافظة.

\section{(المقدمة ( Introduction )}

تعد الزراعة أكثر قطاعات الاقتصاد ارتباطا بموارد الطبيعة إذ تهتم التتمية الزراعية

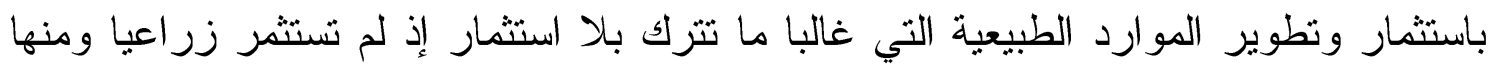

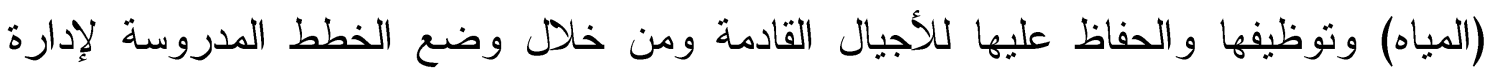

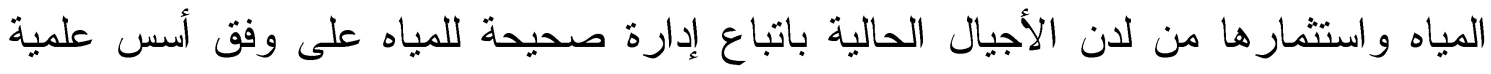

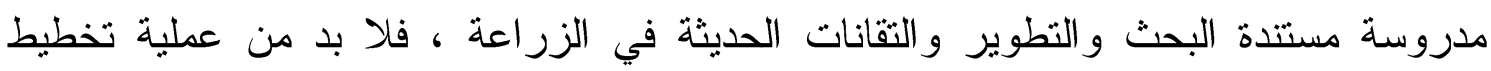
منكاملة ومنتظمة تؤخذ بنظر الاعتبار الموارد المائية المتاحة ومن ثم تحديد جميع الإمكانات

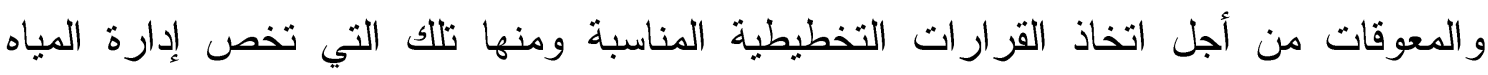
ودور ها في التنمية الزر اعية المستدامة ،اذ تعدالموارد المائيةالى جانب تأثير ها في طبيعة وكمية التئية

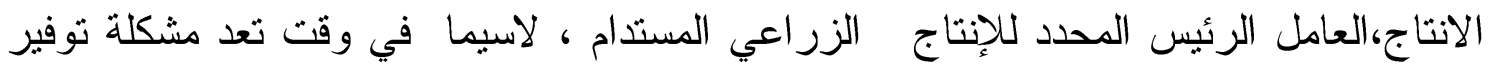
المياه و احدة من أكثر المشاكل تعقيدا على المستويات الدولية والمحلية،وأن تحقيق الأمن المائي لأئي 
هوضمان لتحقيق وتواصل الأمن الغذائي كضمانة للتنمية الزراعية المستدامة التي أصبحت الهدف المنشود لكل سياسة زر اعية.

\section{مشكثة الار اسة (The Problem of study) :}

هل تمثلك المحافظة إدارة مائية تسهر في تحقيق التتمية الزر اعية المستدامة فيها ؟

\section{فرضبة الارسة (The hypothesis of the study)}

كما ذكرنا سابقاً تتو افر في محافظة الأنبار موارد مائية (سطحية وجوفية) بحاجة الى وضع

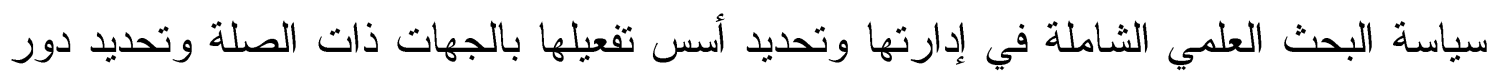

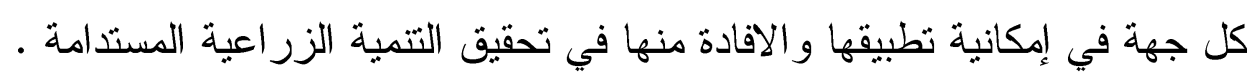

\section{هدف الار اسة ( The aims of the study )}

تهدف الدراسة إلى الكثف عن تو افر الموارد المائية ( السطحية و الجوفية ) في محافظة

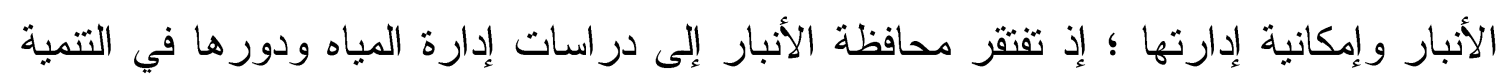

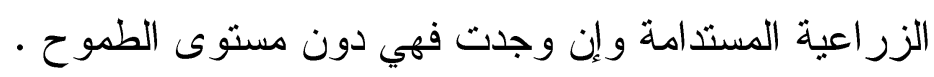

\section{حدود الار اسة (The limits of study)}

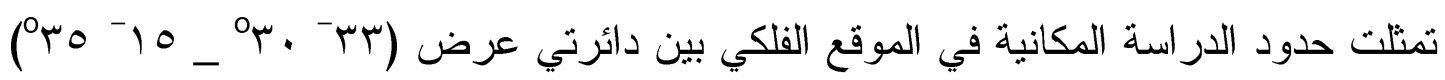

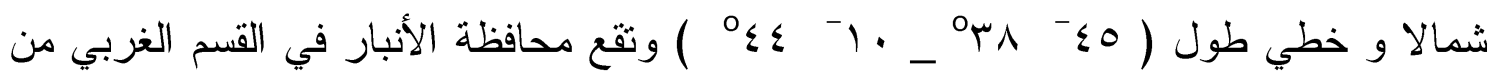
العراق ضمن أراضي الهضبة الغربية الصحر اوية ، ويحدها من الشمال محافظة نينوى وأجزاء

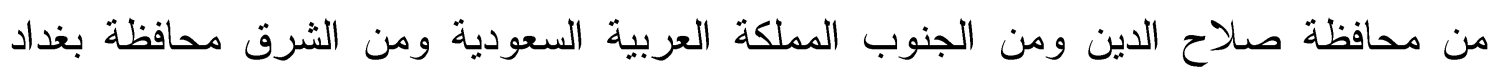

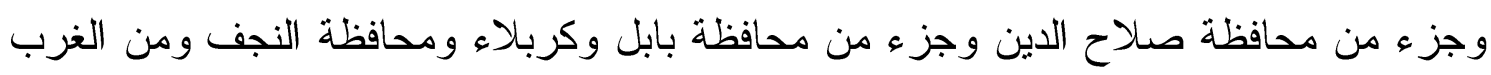

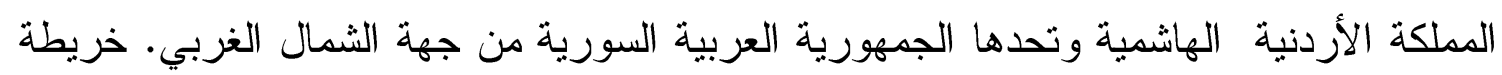

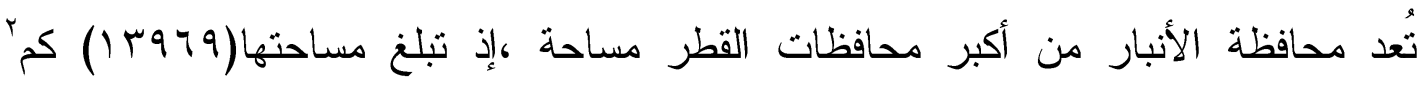

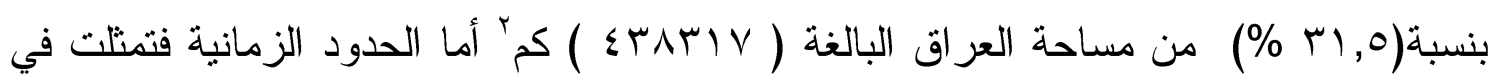

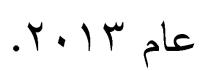


مجل: الآراب / العرد عال|

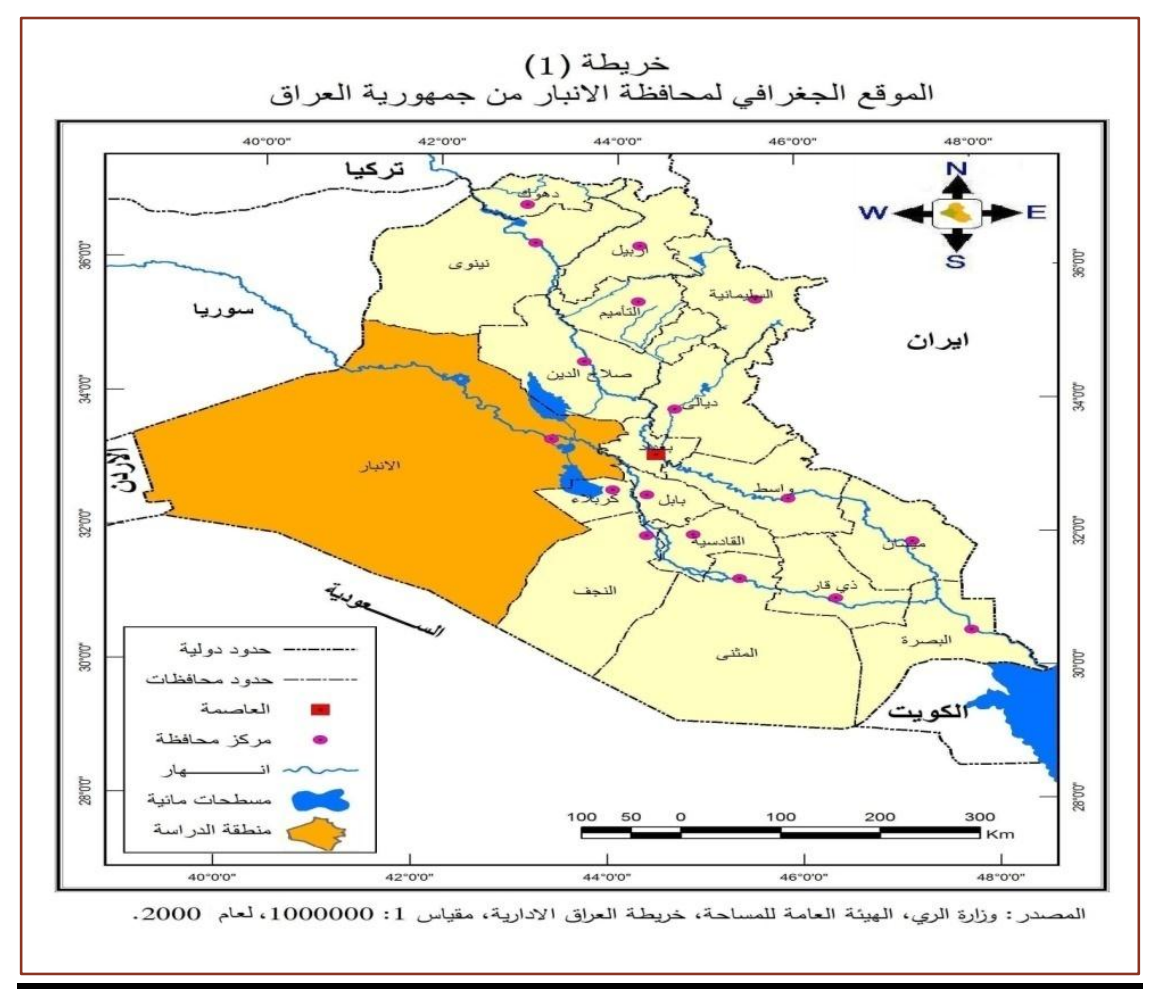

الإدارة المائية ( Water administration )

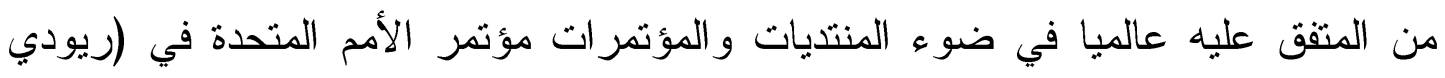

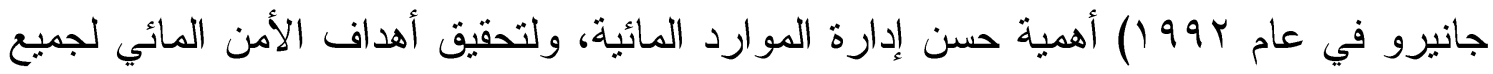

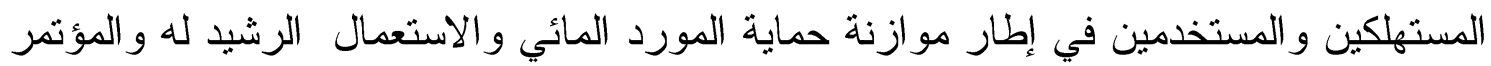

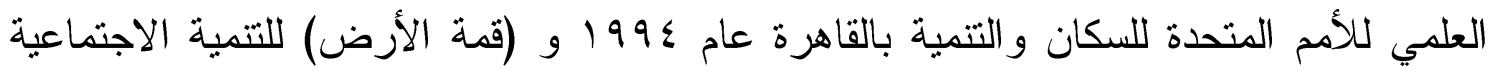

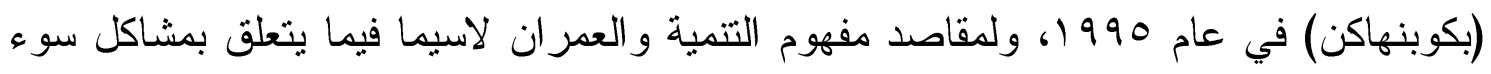

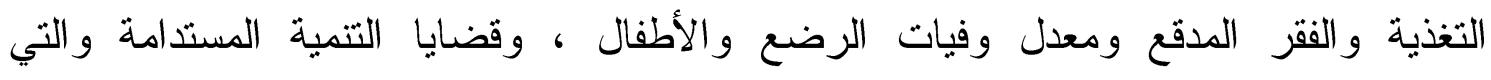

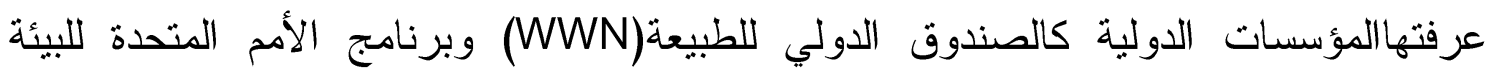

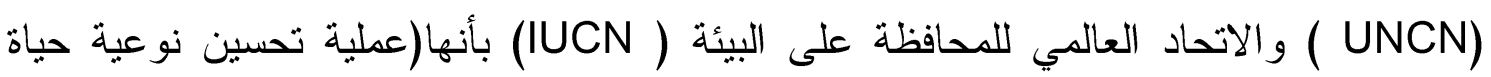

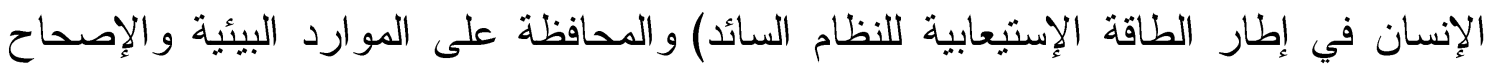

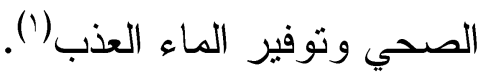


إن الإدارة المتكاملة للمواردالمائية كماعرفتها (IWRM)من قبل الشراكة العالمية للمياه)

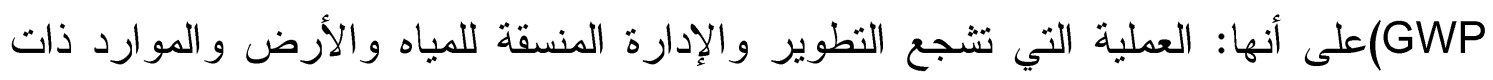

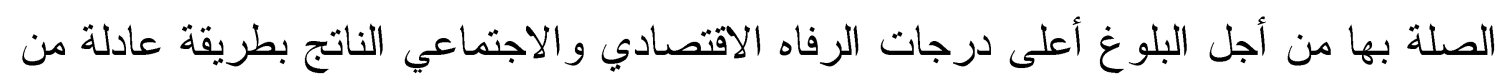

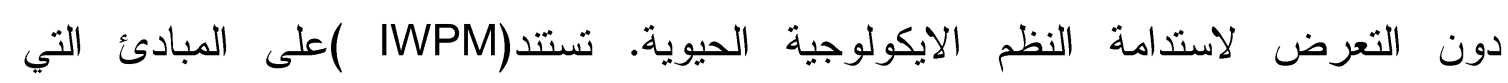

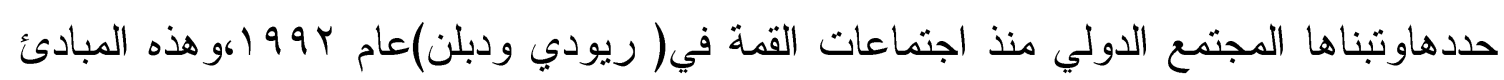

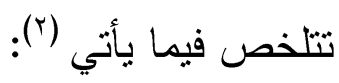

1- المياه العذبة مورد محدود وحساس ،ضروري لدعم الحباة و التتمية و البيئة.

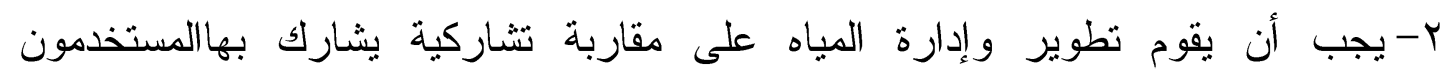

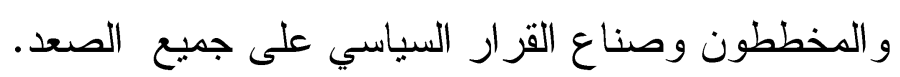

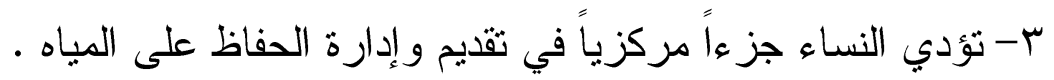

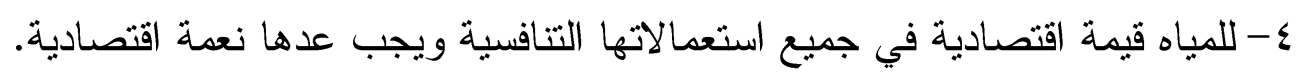

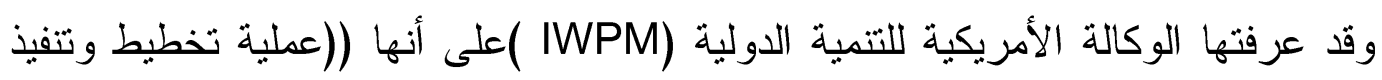

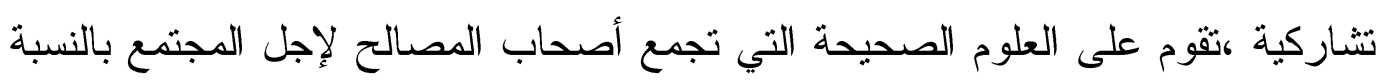
للموارد المائية و الساحلية في الوقت الذي يحافظ فيه على الخدمات الايكولوجية و الفوائد الاقتصادية.تساعد) (IWPM)على حماية البيئة العالمبة وتشجع النمو الاقتصادي والتتمية

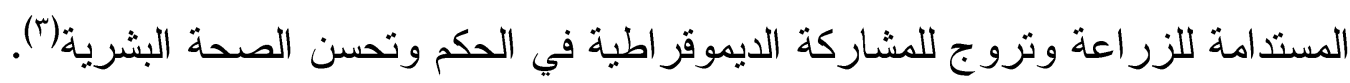

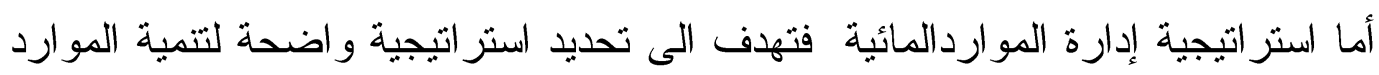
المائيةإذ تكون مسايرة لأهداف المخططات المحلية لكل بلد وعلى سبيل الديل التمثيل للحصر (₹)

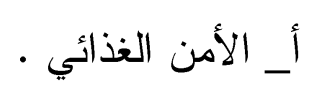

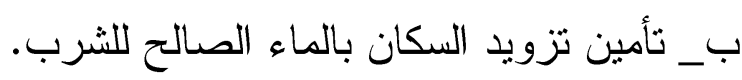
تـ_ المحافظة على الموارد المائية وحمايتها عن طريق وضع أجهزة تشريعية وتتظيمية

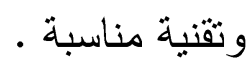
ث_ مر اعاة حماية البيئة الطبيعية ،سعياً الى تحقيق تتمية اقتصادية واجتماعية مستدامة.

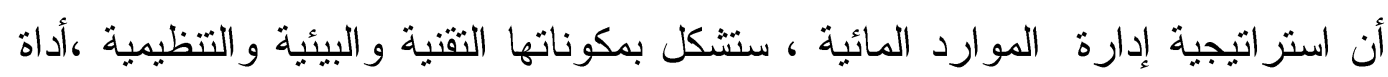
توجيهية تسهل عملية اتخاذ القرار السياسي بهدف إدارة مستدامة للموارد المائية 

$\infty \leqslant r q r \cdot 10$
مجلن الآراب / العدر ع 11

إدارة القطاع المائي : ( Water sector administration ):

تهتم إدارة القطاع المائي بالأفرع المتخصصة بالمصادر المائية وتلك المستعملة للماء على

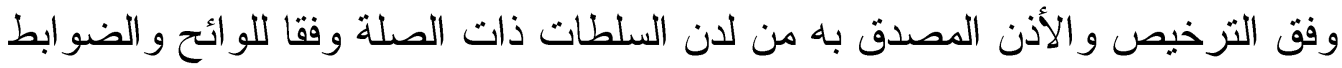

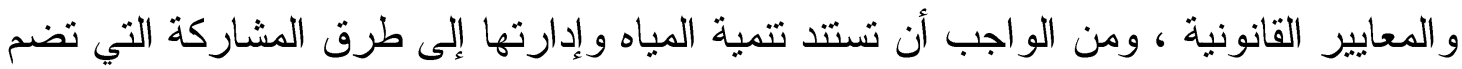

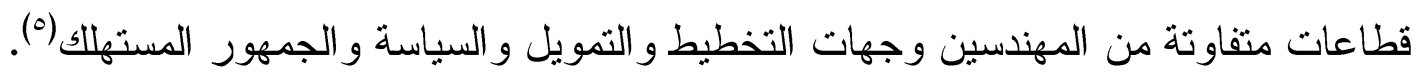
وربما كان من الأنسب أن تقوم كل منطقة حوض ساكب ، أو إقليم مائي بوضع النظم

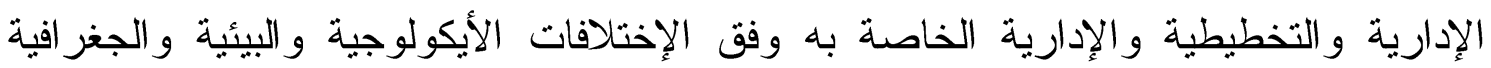
و الفنية و الهيدرولوجية و السياسية والاجتماعية و التقافية السائدة في المنطقة ـ من الأفضل للإدارة

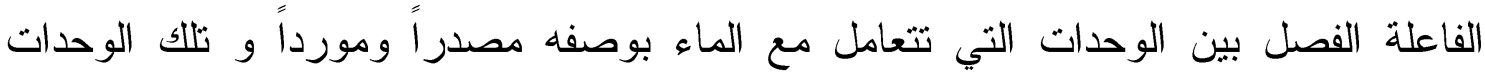

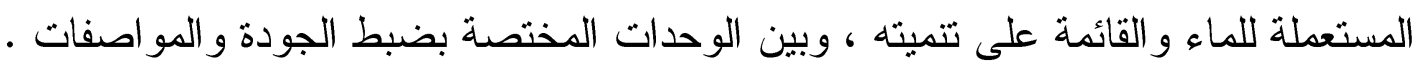

\section{Sustainable Agriculture ) التنمبة الزراعبة المستدامة}

: (Development

$$
\text { عرفتها منظمة الفاو العالميه عام } 1911 \text { : }
$$

إدارة وصيانة الموارد الطبيعية الإنسانية إذ تضمنت المؤسسات و التقانات والمتطلبات

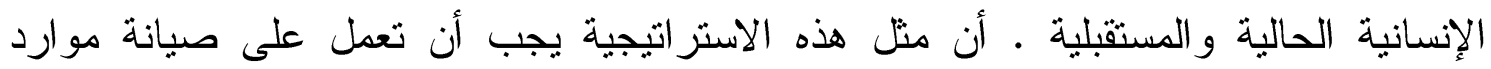
الأرض و المباه والموارد الور اثية النبانية والحيوانية كما يجب أن تكون مقبولة تقنباً و اقتصادياً

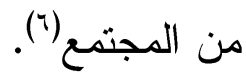

1- إدارة الموارد المائية ودورها في تحقيق التنمية الزراعية المستدامة:

\section{:( Water Resources administration )}

يمثل الماء عنصراً حيوياً في حياة المجتمعات البشرية وتطويرها عبر التاريخ فلا يمكن لأي من الموارد الطبيعية الأخر أن يوازيه من حيث الأهمية والتأثثر في مجرى العوامل المتر ابطة الفعالة التي تجدد نوعية البيئة الطبيعية وشروطها، أن ندرة المياه العذبة وسوء استعمالها تشكل تهديداً خطيراً ومتز ايداً للتنمية ، فصحة الإنسان ورفاهيته وأمنه الغذائي كما التنمية الصناعية و النظم البيئة التي تعتمد علبها هذه العناصر، معرضة جميعاً للخطر مالم تتم إدارة الموارد 
المائية بفعالية تزيد على ماكانت عليه، إن الهدر في المياه وانخفاض كفاءة استعمالها تتطلب

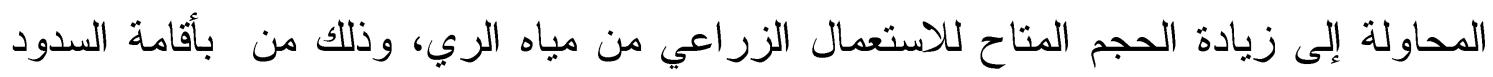

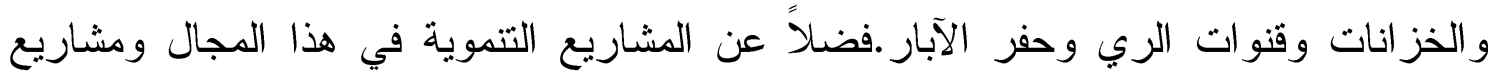

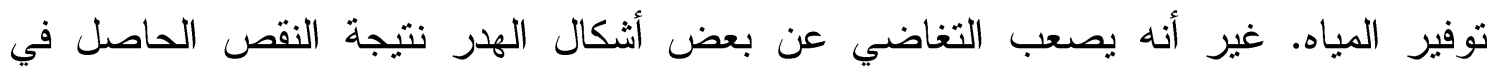

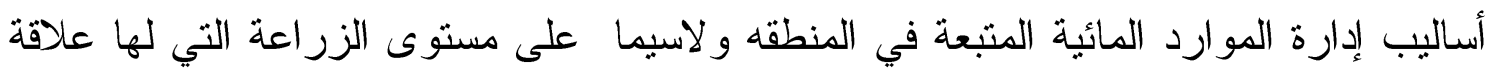
مباشره بنطوير مهار ات وقدرات المزارع على استعمال النظم والأساليب العلمية في إدارة مياه

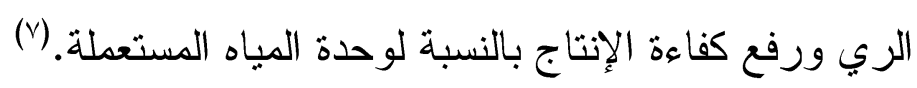

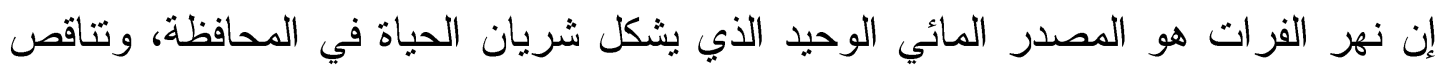

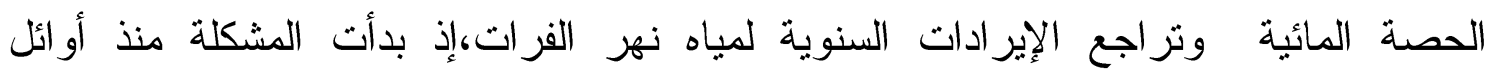

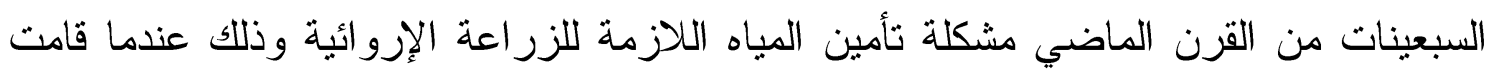

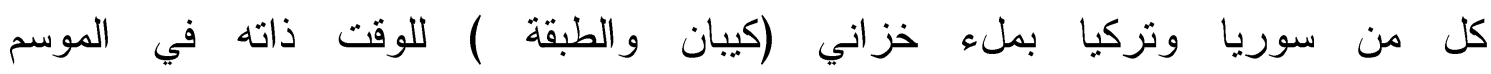

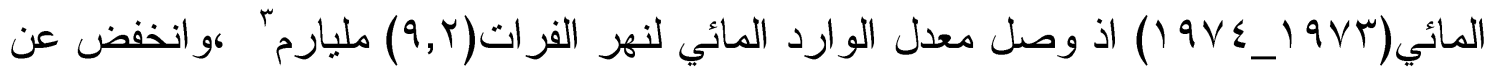

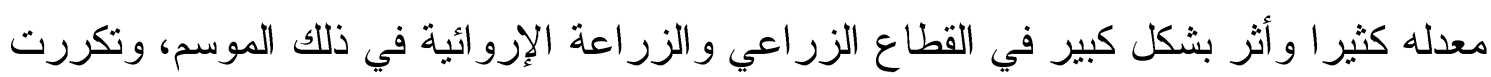

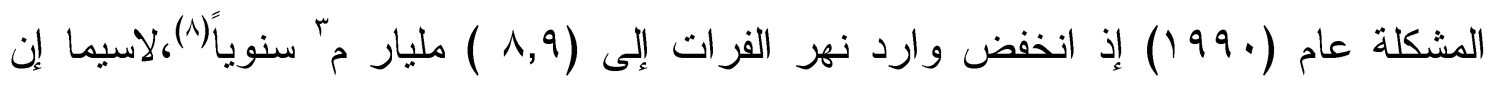

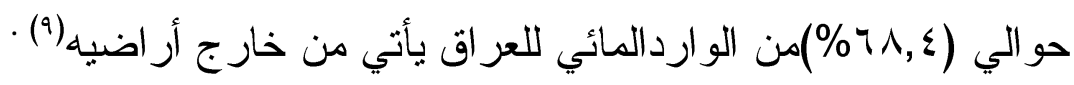
أن هذه المشكلة بدأت تفرض نفسها في القطاع الزراعي في العراق في ضوء الآثار

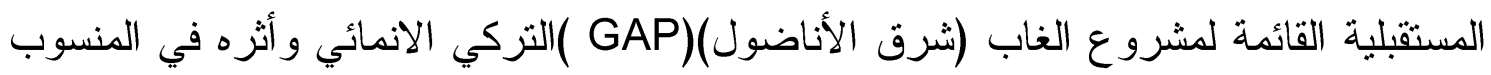

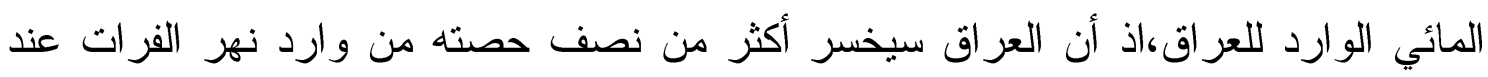

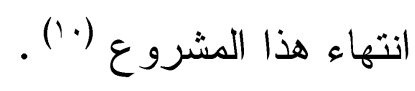

و المشكلة الأخرى أصابة مباه نهر الفرات بالملوحة نتيجة أعمال الري و البزل لكل من

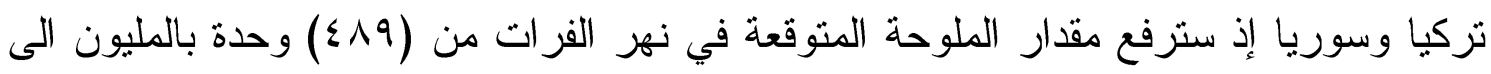

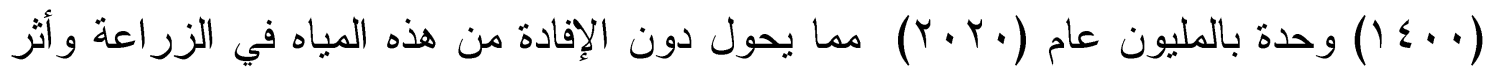

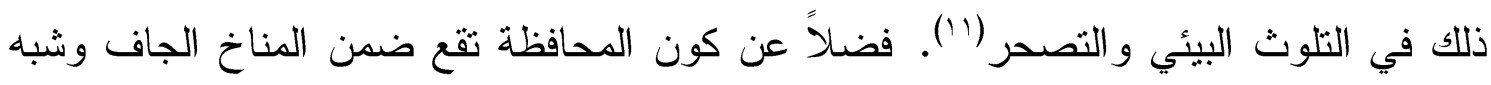

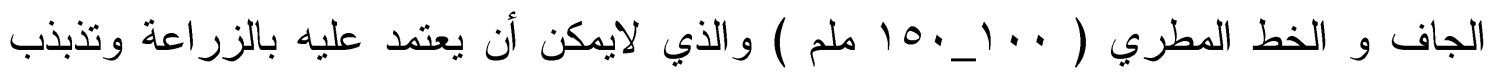

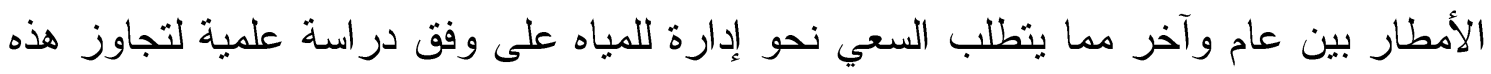

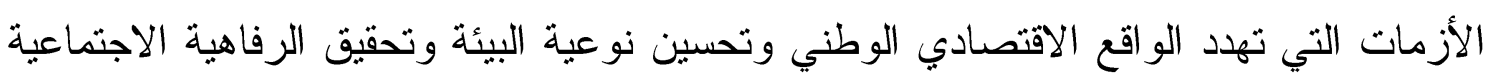

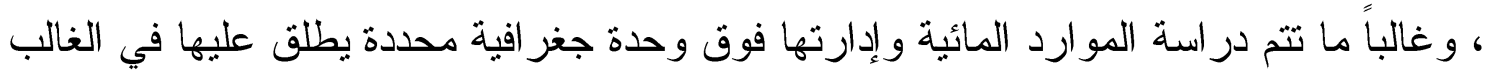


تعبير ( حوض التصريف ) أو ( الحوض النهري ) أو مستجمع الأمطار ، إذ تسهم خصائص

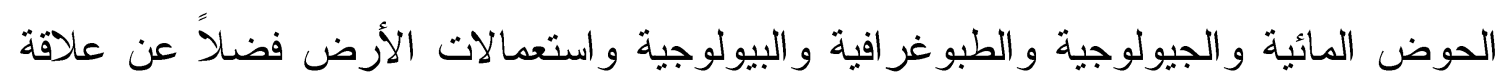

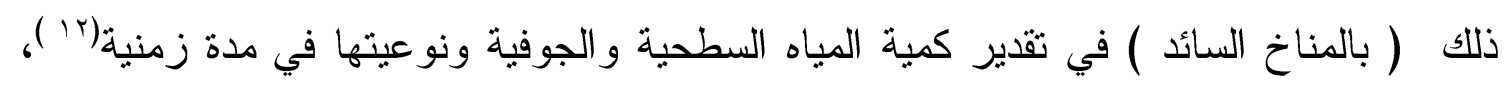
و هذا الأمر يرتبط بتحقيق التتمية الزر اعية المستدامة في المحافظة.

\section{إ_إدارة أزمة مياه نهر الفرات الاقليمية:}

يتطابث دور العراق في أزمة الفرات الإقليمية مع دور سوريا في إدارة تللك الأزمة، فموقف سوريا

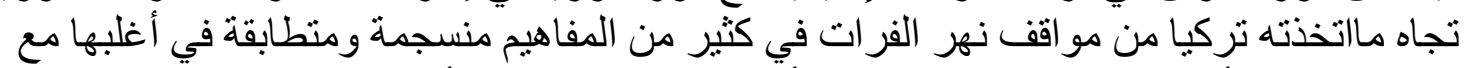

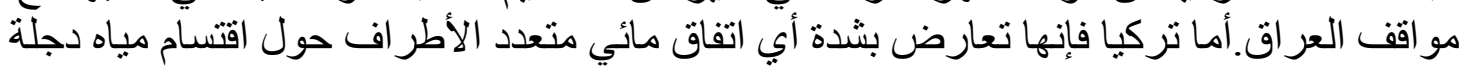

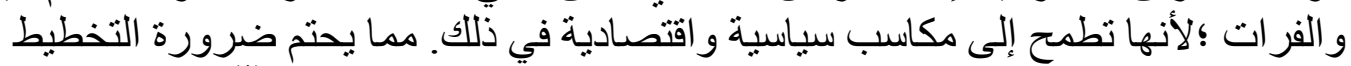

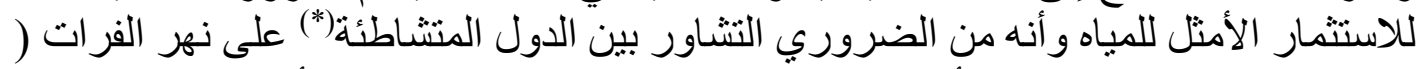

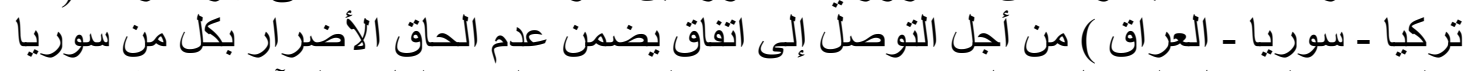

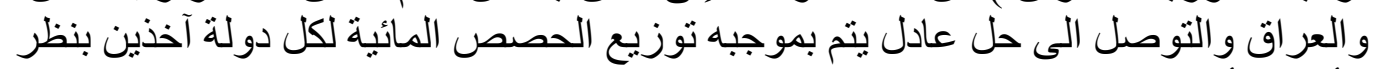

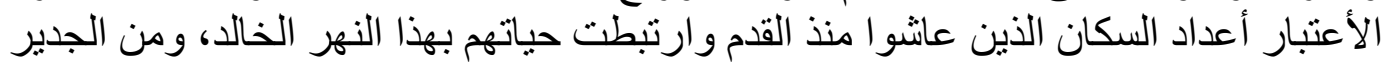

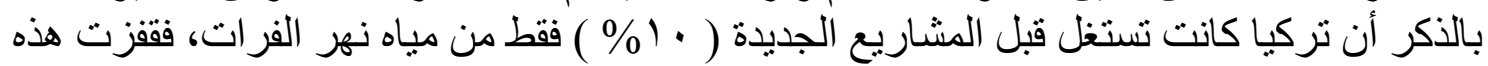

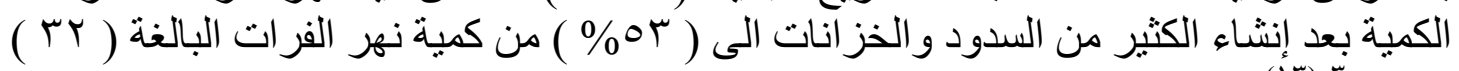

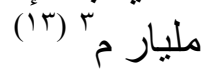

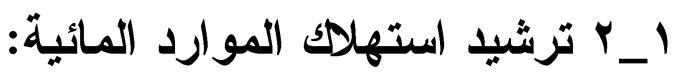

يتوجب على العراق أن يعتمد على الإجراءات العلمية في صيانة وترشيد استهلاك المياه

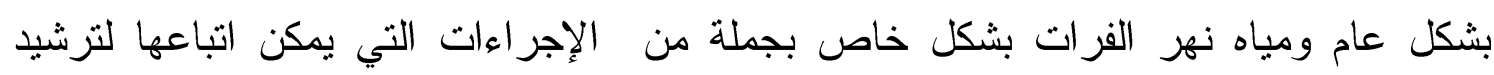

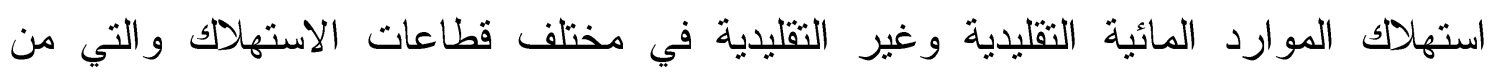
أهمهاما يأتي :

\section{أولا : ترشيا استهلاك مياه الري :}

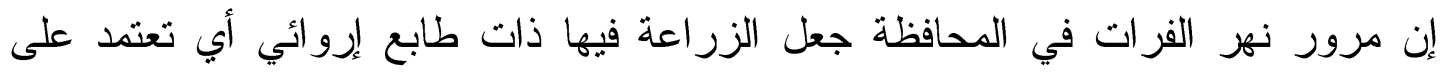

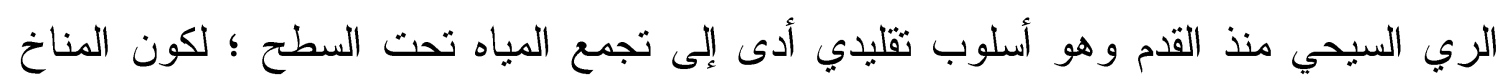

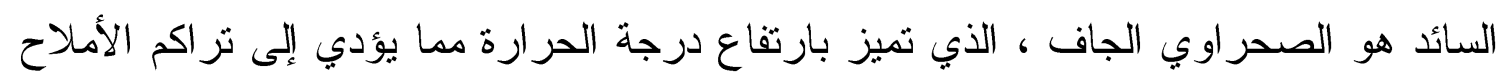

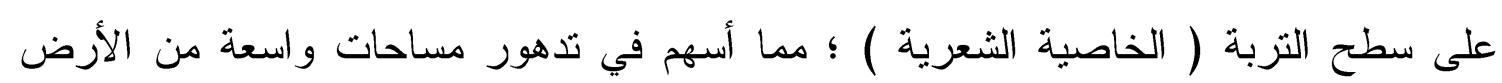

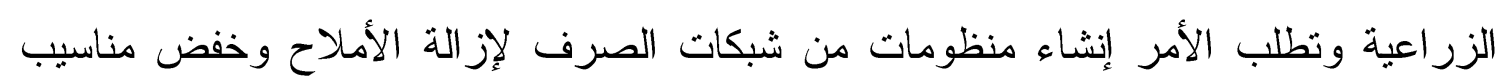

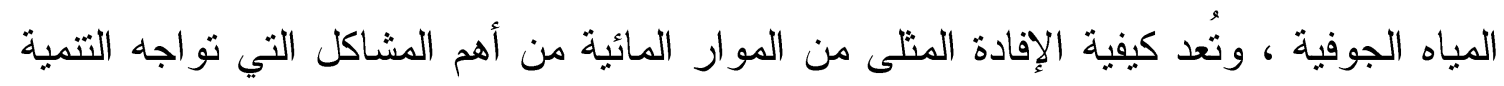


الزراعية المستدامة من أجل التوسع في زراعة المساحات المزروعه حالياءٔ)، إذ يعد تحسين

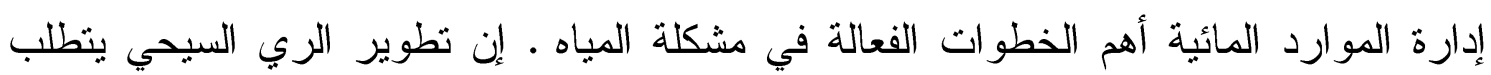

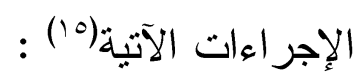

' ـ إعداد بيانات رقمية عن قيمة الاستهلاك المائي للمحاصيل الزراعية وكذلك الدورات الزر اعية الملائمة للتربه و المناخ و هذا يؤدي إلى معرفة الاحتياجات الإرو الئية الحقيقية لمشاريع الري الرز

r _تبطين قنوات الري ليساعد على تقليل الفو اقد من المياه نتيجة الرشح من القنوات . rـ إجراء عمليات التعديل والتسوية باستعمال الآلات والأجهزة الحديثة في الحقول الزر اعية مما يحقق الري بشكل متجانس وتقليل هدر المياه .

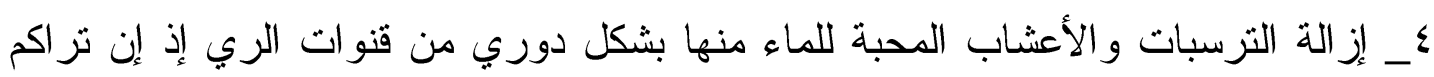

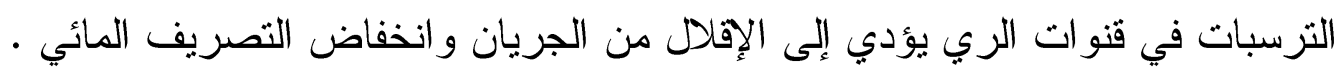
•ـــ إدخال أساليب الري الحديثة ( الرش و التتقيط ) و التقليل من استعمال الطرق التقليدية في الري . ؟_ نقل المياه بأنابيب بدلاً من نقلها بقنوات مكشوفة ، مما يقلل تبخر المياه وتلوثها بالأتربة و غير ها. Y_اعتماد الري المقنن للمحاصيل الزر اعية واعتمادطرق الري الحديثة بالرش و التنقيط.

\section{ثانياً: صيانة مشاريع الري :}

إن استعمال أسلوب الري بالمرشات القديمة يؤدي إلى خسارة كبيرة بالمياه نتيجة التبخر ،

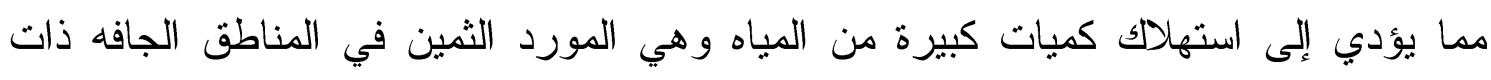

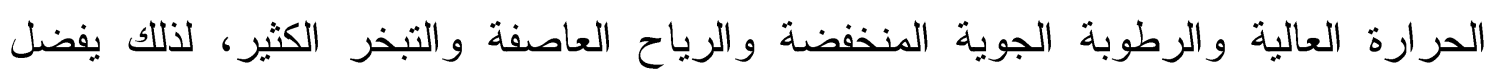
استعمال أنظمة الري الحديثة وهي (17) :

\section{أ_ـ أنظمة الري بالرذاذ (Sprinkler irrigation Systems)؛}

'_ شبكة أنابيب سطحية مرشات ( Surface pipes with Sprinklers ). 
r جهاز الملفات الآلي ( Automatic reelmachine ).

بـ_ الجهاز المحوري ( Center pivot ).

عـ الجهاز الجبهوي ( Lateral move ).

ب_ أنظمة الري الموضعي ( Localized irrigation Sysreres ) :

'_ المرشات الصغيرة ( Micro sprayers \& Micro sprinklers \&Mini Dripess ).

( Dripess ) ( نقاطات

ج - الري السطحي المطور (Improved Surface irrigation )

' ـ الري باستعمال الأنابيب الناقلة و البو ابات ( Gate pipes ) .

بـ الري المتقطع ( Surge Flow ) م

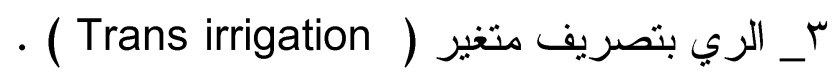

أصبحت مسألة تطوير وتحسين وتفعيل دور إدارة الموارد المائية مطلبا بل شرطا ضروريا

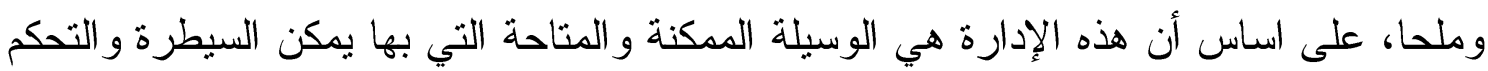

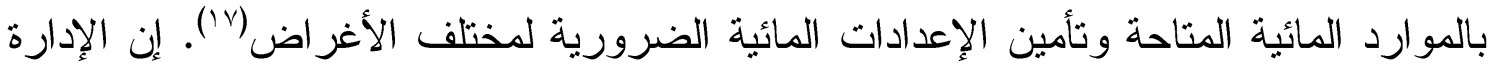

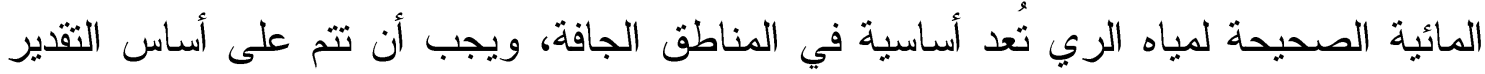
الصحيح لعنصرين أساسين بغية المحافظة على حركة الأملاح باتجاه الأسفل و هها:

1- الاحتياجات النباتية من الماء ( التبخر / النتح ) .

r- احتياجات الغسل تبعاً لنوع التربة ومو اصفات الماء .

ثالثا : ترشيد استهلاك مياه الاستخدامات المنزلية :

تشمل مياه الاستعمالات المنزلية مياه الثرب والطبخ والمياه المستهلكة في دورات المياه

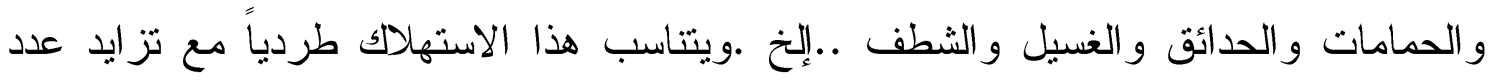
السكان، وتطور مستوى المعيشة وطبيعة التشريعات المنظمة لاستهلاك المياه داخل التجمعات 
السكانية ومدى وفرة المياه وطريقة نقلها إلى داخل التجمعات السكنية، مع مر اعاة ايجاد سياسة

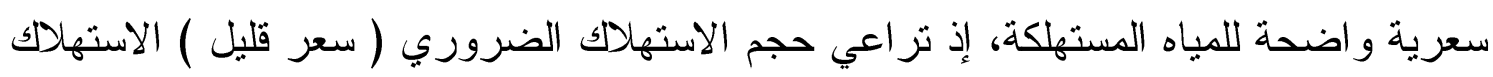

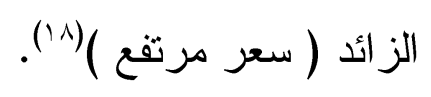

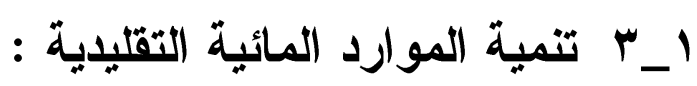

ويتم ذلك عن طريق اتباع اجر اءات مختلفه منها :

\section{أولاً _ حصاد مياه الأمطار ( Water harvesting ) :}

يطلق مصطلح الحصاد المائي( Water harvesting ) على أية علية مورفولوجية أوكيميائية أوفيزيائية تتفذ على الأرض من أجل الإفادة من مياه الأمطار، سواء بطريقة مباشرة الئرة

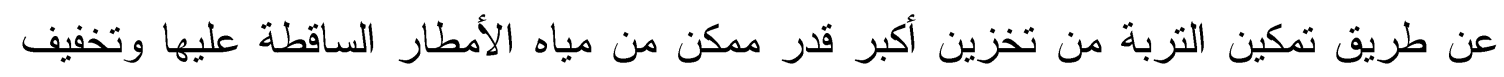

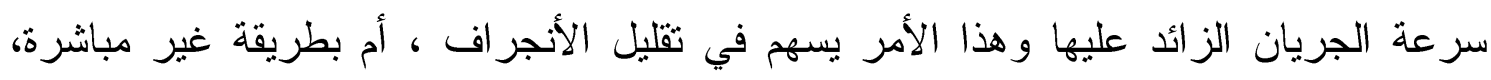

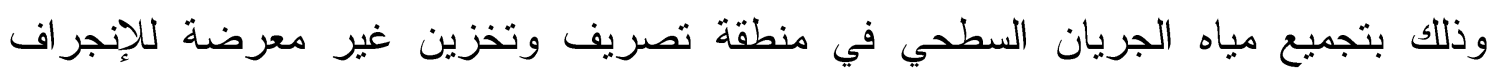

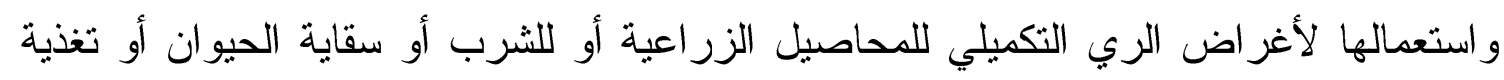

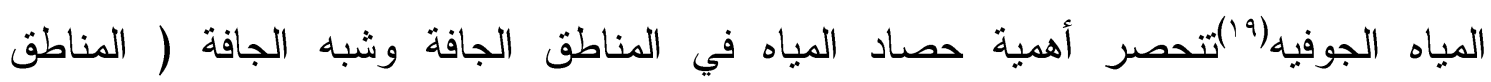

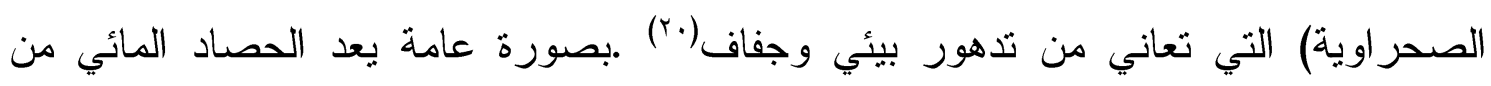

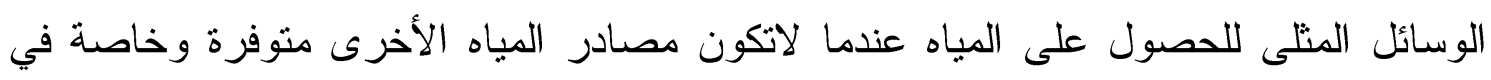

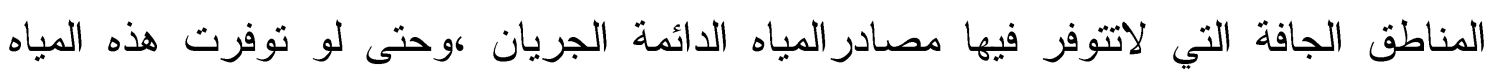

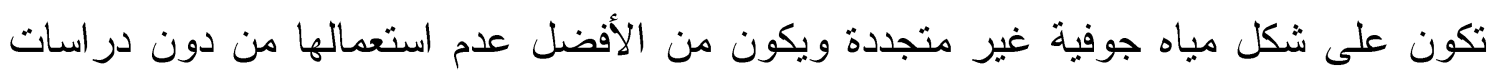

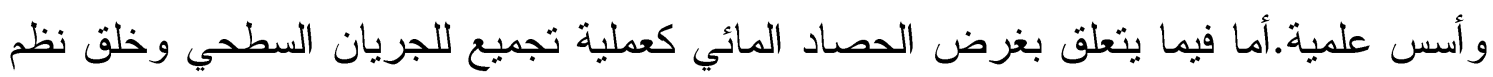

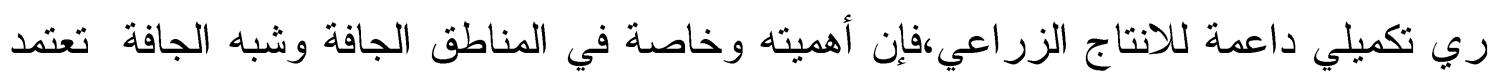

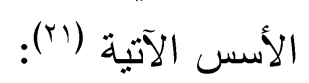

• ضرورة أن يكون الحصادالمائي مصدراً مكملاً (ري تكميلي) للنقص في المواردالمائية

$$
\text { وليس المصدر الوحيد للمحاصيل ذات الاحتباجات المائية العالية. }
$$

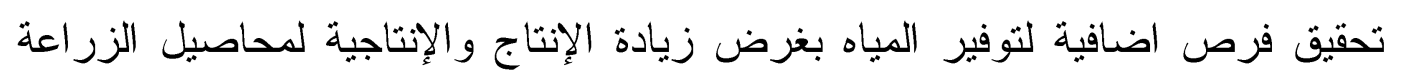
المطرية.

تحقيق زيادة كفاءة استعمال الموارد الأرضية غير المستغلة . 
ومن الحقائق التي يجب أخذها بنظر الاعتداد في مجال الحصاد المائي أنه وفي المناطق

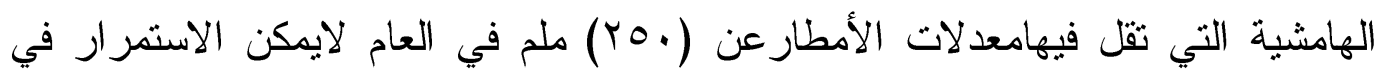

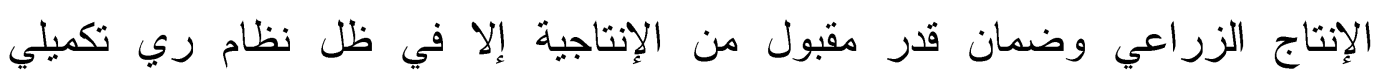

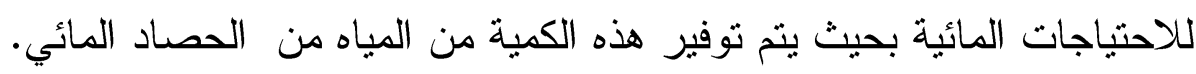

إن الترويج لتبني تقانات حصاد مياه الأمطار يأتي من واقع بساطتها وسهولة تتفيذها بأقل

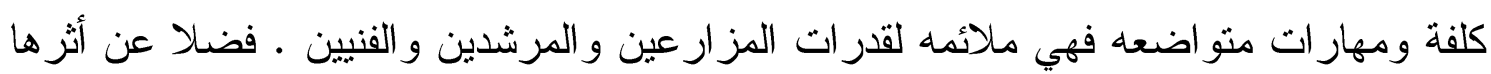

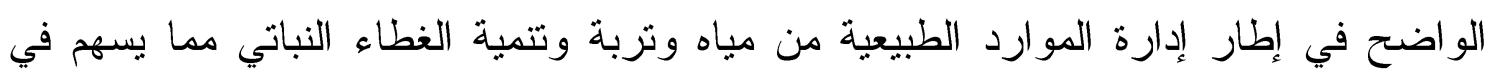

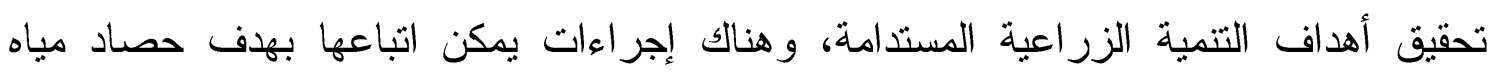

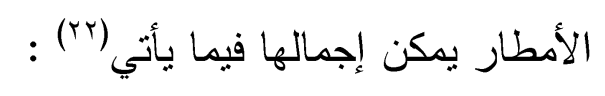

'_ بناء جدران من الأحجار عبر المنحدرات لـنع انجراف التربة وحفظ مياه الأمطار

؟ _ إنشاء حفر للزر اعة تساعد على تزكيز الأمطار الهاطلة حول الأشجار و النباتات . و بـ استعمال حواجز من الحشائش غزيره النمو بدلا من الأحجار لتبطئ سرعة الجريان

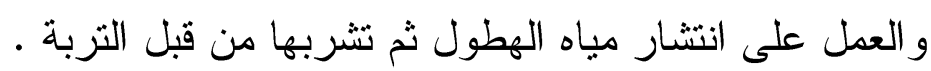
ع_ تحويل الهضاب إلى أشرطة ومصاطب .

ه_حصاد المياه من المنحدرات الثديدة بتوجيه مياه الجريان السطحي عن طريق (حواديد

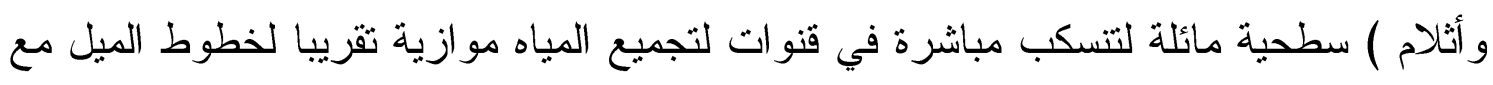

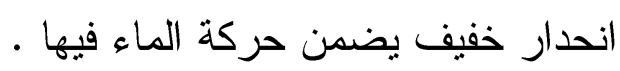
؟ توجيه مياه الأمطار في الدنحدرات الخفيفة إلى أراضي قاعية أوفيضية باستعمال حو اديد طويلة . V _ توجيه مياه الأنهار في المنحدرات المتوسطة إلى قنوات تجميع ، ثم الأراضي الزراعية أو الصهاريج · توحيه

^_ إنثاء الخزانات المائية الجوفية في جوانب الوديان ، بإنشاء سدود صغيرة بهدف رفع مستوى الماء في مجرى الوادي . 
9_ عمل حفر عميقة في الوديان لتجميع المياه إذ يتحول إلى برك بعد انقطاع جريان الوادي

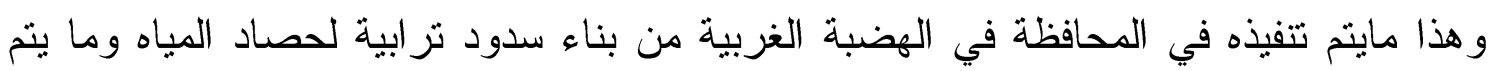
كذلك من خطط استثمارية في حوض الحماد باستخدام الخطوط الكنتورية والسدود التزابية في

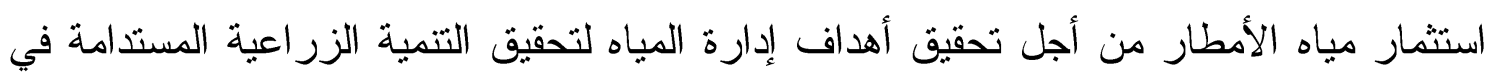

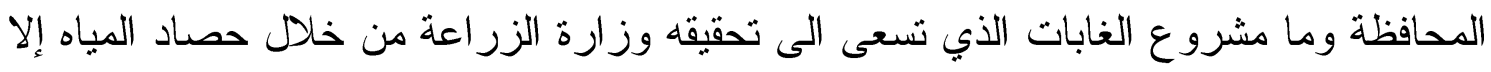

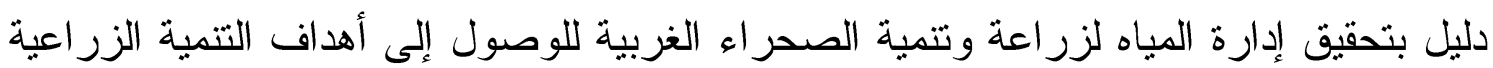
المستدامة بأبعادها الثلاثة الاقتصادية والاجتماعية و لإلبيئية(rr).

•_ وضع الخطط لحصاد المياه باستعمال تقانات الاستثعار عن بعد ونظم المعلومات

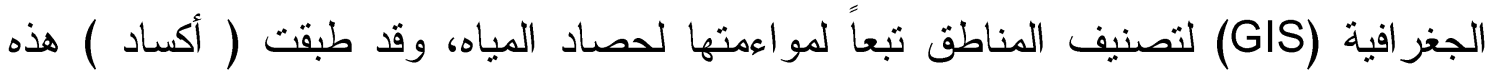

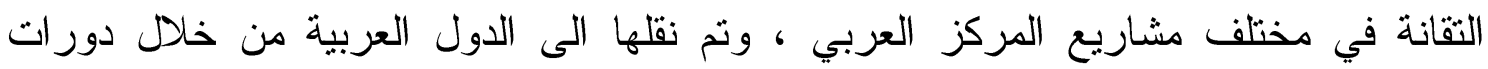

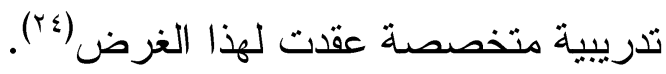
وعموما فان مشاريع حصاد مياه الأمطار يمكن ان تحقق الأهداف الآتية: (ro). توفير عامل الاستقرار لسكان مناطق هذه المشاريع والمناطق المجاورة ورفع مستوى

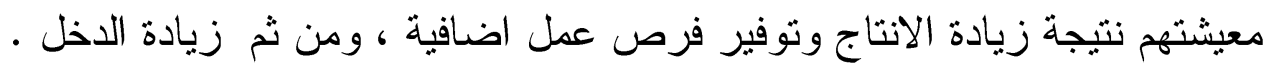

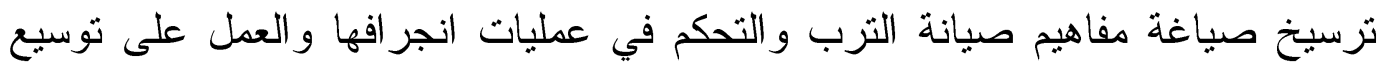

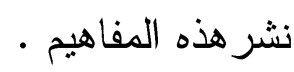

نقل تقانات حصاد المياه لمشاريع رائدة الى مناطق مثيلة وتحقيق الانتشار الو اسع بها. دعم برامج الأمن المائي والأمن الغذائي في المنطقة.

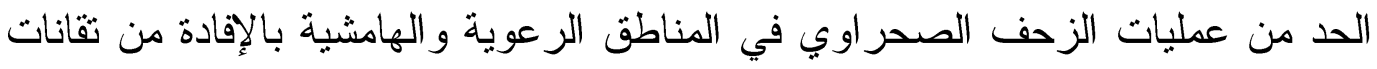
حصاد المياه على وفق الظروف السائدة في المنطقة بما يكفل التوازن البيائي بها. تدريب الكوادر الفنية على تقانات حصاد المياه ونقل وتبادل تكنولوجيتها.

\section{ثانيا : الحفاظ على المياه الجوفيه وصياتتها :}

تتصف الموارد المائية بتجددها المستمر في الدورة المائية ، إلا أن التذبذب في كميات الأمطار وتتاوب دورات الجفاف في المناطق الجافة وشبه الجافة أمر محتم ينطلب الاستعمال

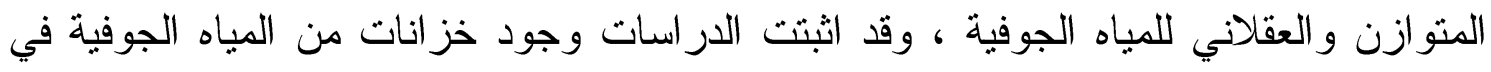

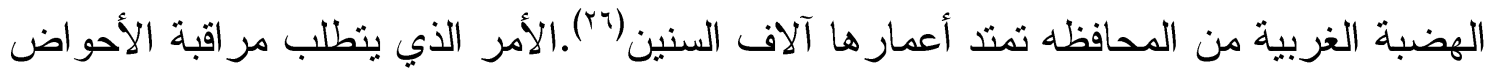


المائية الجوفية التي سيباشر باستثار ها من الناحيتين الكمية والنوعية كما يجب زيادة التغذية الاصطناعية للمياه الجوفية، وذلك بإنشاء سدود ثرابية أخرى على الوديان ومن الضروري بلهي الاستمر ار في البحث و الكثف عن خزانات مائية جوفية جديدة ، ثم وضع خطه للإفاده من المياه الجوفية على أن تكون متكاملة مع إدارة المياه السطحية ؛وذلك الدعم الكامل لعملية التنمية

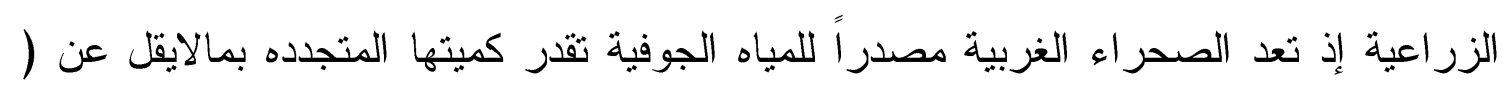

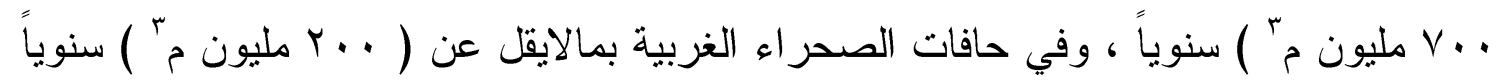
وبهذا يصل الخزين إلى ( مليار مم ) تقريباً، علماً بأن كمبة المباه المستثرة في المنطقة قليلة جداً قياساً بما هو متوفر من احتياطي، وأن المساحات التي يمكن إرواؤها بالاعتماد على الخزين المتجدد وباستخدام الري ب(الرش المحوري ) في الصحر اء وحافاتها الغربية تبلغ ( ....0س؟) دونم ويمكن إضافة حوالي ( . . ...0) دونم عند استخدام جزء بسيط من الخزين الثابت للمياه الجوفية وبذلك تصل المساحة التي يمكن إرواؤها إلى حدود المليون دونم (YV) مما بسهم في دوني تحقيق تتمية زر اعية مستدامة في المحافظة إذا نظافرت الجهود للنهوض بالواقع الزر اعي بشقيه النباتي و الحيو اني و هوما يسهم في الدخل القومي.

\section{ثالثاً : تشييد السدود ( Barricades building ) :}

تعد الأعمال التتظيمية التي تخضع لها مياه الأمطار و المياه الجارية السطحية عن طريق إقامة السدود الصغيرهو المتوسطة والكبيرة من الأمور المهمة جداً في حفظ المياه وصيانة مواردها المتجددة و زيادتها، إذ تتدفق كميات كبيرة من المياه العذبة بيسر وسهولة إلى مصباتها في البحير ات المالحة أو السبخات وتتبخر من غير أن يفاد منها، تشكل السدود إحدى التقانات القديمة نسبياً التي تستعمل أيضاً في حصاد مياه الأمطار الناتجة من مياه السيول التي تجري في الأودية خلال فصل الأمطار إذ يمكن حجزجميع هذه أو جزء منها في المواقع المناسبة ضمن مسار الأودية وتكوين بحير ات صناعية صغيرة أو منوسطة. تبنى من مواد نزابية أو أو ركامبة(مع نواة غضارية كتيمة ) على المجاري المائية (وديان ، مجاري سيول). ويتم تحديد موقع السد و أبعاده اعتماداً على در اسات هيدرولوجية وطبو غر افية وجيولوجية

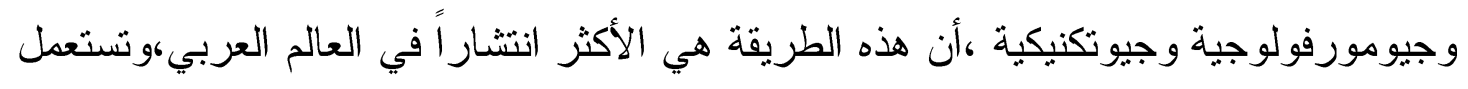
مياههالأغر اض الشرب وسقاية المو اشي وري المحاصيل الزر اعية،وقبل الشروع بانشاء السدود لابد من إجر اء در اسة و افية تتضمن مايأتي (r^): 


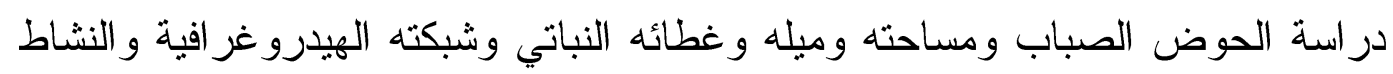
البشري الذي بمارس. • دراسة وتحليل الهطل المطري واحتمالية وتحديد حجم الجريان السطحي. در اسة التذفقات العظمى وتحديد الموجات الفيضانية. هر اسة العناصر المناخية المختلفة وخصوصاً التبخر و التبخر_نتح.

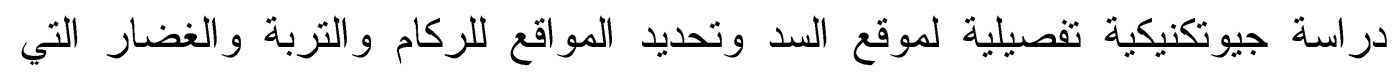
تستعمل في بناء جسم السد. تصميم السد (تحديد عرض قاعدة السد وقمته و الميل الجانبي وارتفاع السد وخط الرشح و اتزان السد).

تزداد أهمية بناء السدود على الوديان المتواجدة في الهضبة الغربية من المحافظة لكونها

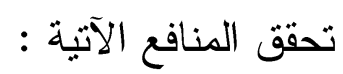

' خزن كميات من مياه الأمطار في بحير ات خلف تلك السدود بدلاً من أن تتساب بكميات

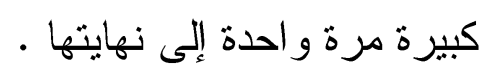

ץ__ إمكانية الإفادة منها لأغراض الري والثرب للقرى وسكان البدو في الصيف كما

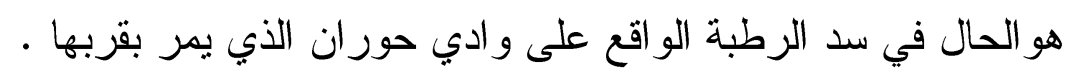
rـ_ يمكن أن تؤدي إلى عمليات استقرار طوعي لسكان البدو ومن ثم السيطرة الإدارية

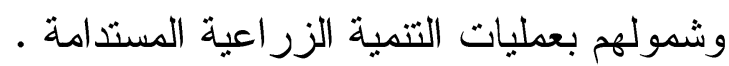

عـ_ الحد من انجر اف التربة نتيجة الجريان الثديد للمياه ونقل التربة الجيدة الصالحة للزر اعة

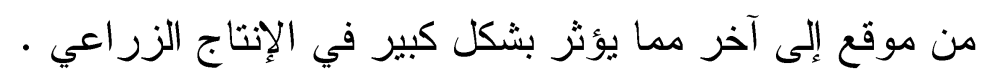
ــ الحد من آثار الفيضانات على المزارع القريبة وتخريب الطرق والحد من الهدر في مياه

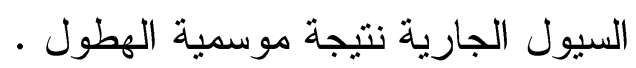

؟ _ تحسين تغذية المياه الجوفية عن طريق الرشح ضمن بحير ات التخزين للسدود كالسدود 
جلي: الآراب / العدو ع11

Y_ بالإمكان استعمال بحير ات السدود لتربية الأسماك كناتج ثانوي يقام لهذه الغاية .

^__تحسين المحيط الذي يتضمن اعندال الجو وحباة الطيور والحيوانات و النباتات الطبيعية

في مدى يتعدى الحدود الجغر افية للو ادي و البحيرة كمحيات طبيعيه نباتية وحيو انية .

9_ تجديد التزبة و المياه و المحافظة عليها من التزسبات من أثغال حصاد ونشر المياه .

. _ الحد من آثار التلوث بإنثاء الأحزمة الخضر اء من الأشجار المقاومة للجفاف والمتحملة

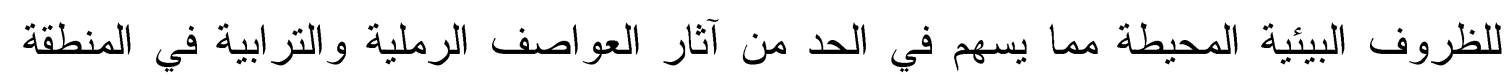
و المحافظة .

تشير الدراسات إلى أن المياه الجوفية في شمال الصحراء بالقرب من ( الحدود السورية )

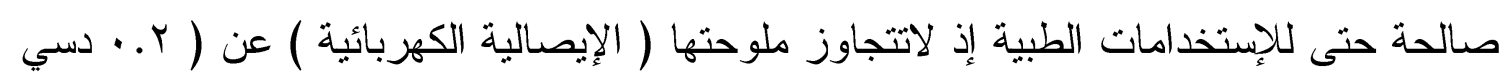

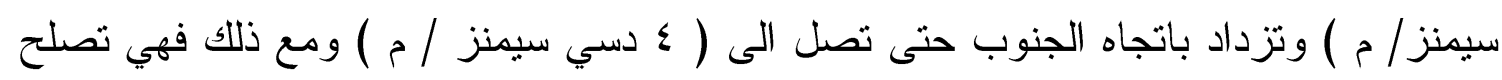

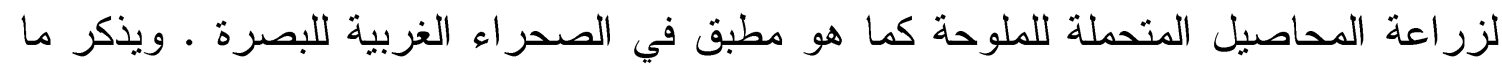

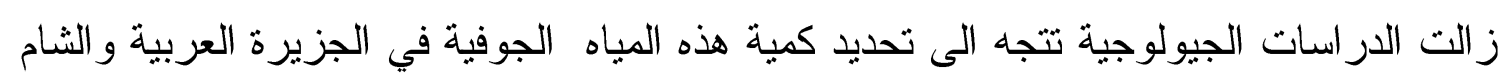

وتُعد المياه الجوفية مصدراً استر اتيجياً رديفاً لمياه الأمطار المخزونة في السدود المقامة في المحافظه ويشير الجدول ( () الى السدود ومو اقعها ومخزونها المائي. 


\section{جدول (1)}

السدود الصغيرة الدقامة في محافظة الانبار لخزن مياه الأمطار

\begin{tabular}{|c|c|c|c|c|c|c|}
\hline الخزن مليون & $\begin{array}{c}\text { ارتفاع السد } \\
\text { (م) }\end{array}$ & $\begin{array}{c}\text { طول السد } \\
\text { (م) }\end{array}$ & الانجاز & 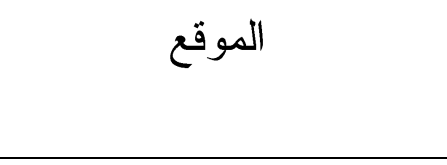 & اسم السد & $ت$ \\
\hline rY & 19 & $\wedge \wedge \varepsilon$ & 1911 & الرب كم جنوب غربي & 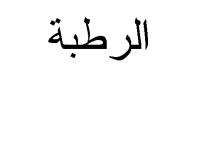 & 1 \\
\hline$\varepsilon$ & 11,0 & $0 .$. & $19 \mathrm{VT}$ & 10 كم شمال الرطبة & الأبيلة & r \\
\hline 7 & 11 & oro & $19 V \varepsilon$ & هـ كم شمال غربي الرطبة & الأغري & r \\
\hline 7 & $1 T, y_{0}$ & 014 & $19 \times 7$ & • م اكم شمال شرق الرطبة & الحسينية & $\varepsilon$ \\
\hline$\wedge$ & $1 \cdot, 0$ & $V Y$. & $19 \mathrm{VV}$ & 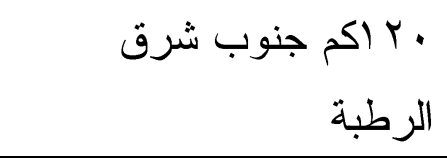 & شبيحة & 0 \\
\hline$\varepsilon$ & 14 & $\varepsilon \varepsilon$. & 1914 & ؛ اكم شمال الرحالية & الرحالية & 7 \\
\hline V & 11,7 & 99. & $19 \wedge r$ & • عكم شمال غرب النخيب & أم الطرفات & v \\
\hline$\cdot, \cdot r$ & 0 & or. & 1987 & • ع اكم جنوب الرطبة & سري سري & $\wedge$ \\
\hline ro & $r$. & Ko. & $r \cdots r$ & • بكم جنوب شرق النخيب & الأبيض & 9 \\
\hline $0, r$ & 10 & $\varepsilon \Sigma \wedge$ & $r \ldots r$ & 1مكم شمال شرق الرطبة & حور ان & 1 . \\
\hline
\end{tabular}

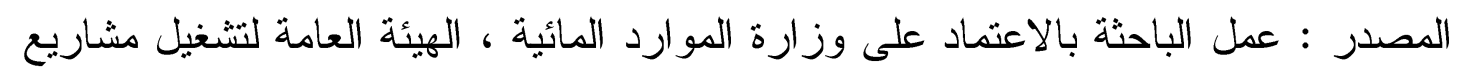

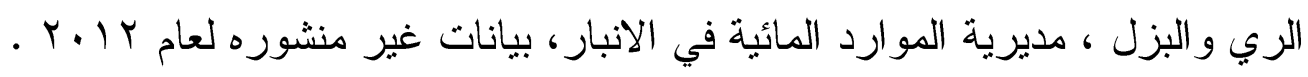

وقد أنجزت ثلاثة سدود صغيرة في الصحر اء الغربية من أجل الحفاظ على مياه الأمطار

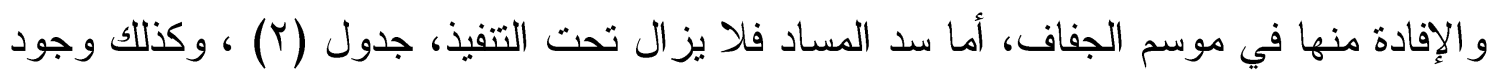
دراسات لتصاميم جاهزه لسدود ستتفذ في المنطقة مما يسهم في إدارة المياه الهاطلة بطريقة

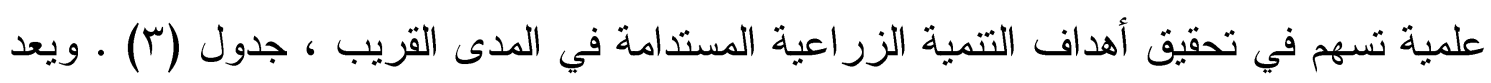
سد (المساد) من السدود المهمة إذ يتم تتفيذه من لدن شركات القطاع الخاص في محافظة الأنبار

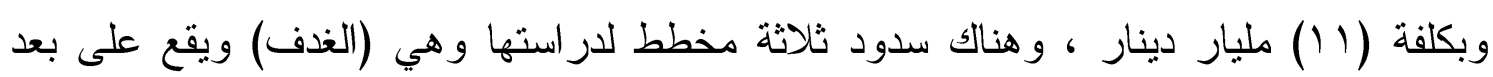

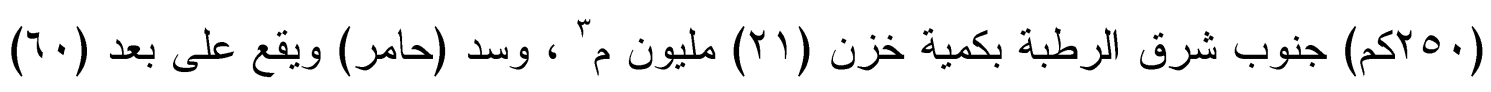

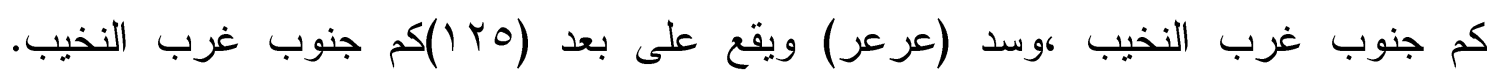




\section{مجل: الآراب / العرد ع1)}

وبالإمكان الاستثمار في انشاء السدود لغرض خزن المياه والاستفاده منها في تتمية المنطقة ـ إن الاستمرار بالبحوث العلمية التطبيقية من لدن المؤسسات المختصة وطلبة الدراسات العليا في ضوء البحث الحقلي النطبيقي يسهم في إقامة السدود على الوديان من أجل استثمار مياه الأمطار

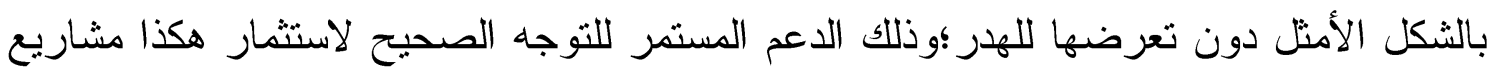

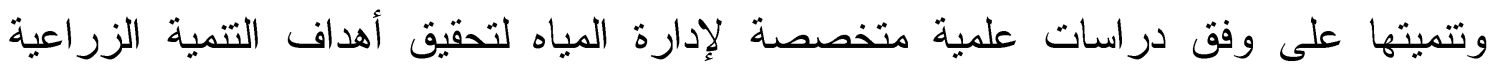

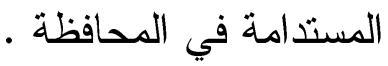

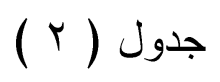

السدود الصغيرة المنفذة في محافظة الانبار لخزن مياه الأمطار

\begin{tabular}{|c|c|c|c|c|c|c|c|}
\hline ملية كليون مئم & قمة السد & قرة السد & جسم السد & تاريخ الانجاز & موقع السد & اسم السد & $ت$ \\
\hline$\varepsilon, 9$ & م09. & 5 & م... & $r \ldots v / r / 10$ & شمال شرق الرطبة(·كم) & سد حور ان/r & 1 \\
\hline$r, v_{0}$ & ك & $5_{\lambda}$ & م077 & $r \cdot 11 / \Lambda / r 1$ & شمال غرب الرطبة (. . اكم) & سد الكعر/مء & r \\
\hline$\varepsilon, Y$ & ما & م & م701,0 & $r \cdot I r / T / 1$ & شمال غرب الرطبة(•• اكم) & سد الكعرم/r & r \\
\hline v & $\rho^{T \Lambda \nu, 0}$ & $5^{3}$ & pror & تحت التنفيذ & جنوب الرطبة ( مr كم ) & سد المساد & $\varepsilon$ \\
\hline
\end{tabular}

المصدر: عمل الباحثة بالاعتماد على دائرة المهند المقيم للسدود الصغيرة في الصحر اء

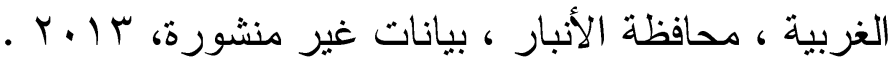




\section{مجل: الآراب / العرد ع1)}

$$
\text { جدول (r) ( ) (r) }
$$

السدود الصغيرة جاهزة التصاميم في الهضبة الغربية لهحافظة الانبار

\begin{tabular}{|c|c|c|c|c|c|c|c|}
\hline \multirow{2}{*}{ تصريف المياه م"|ثا } & \multicolumn{3}{|c|}{ معلومات فنية } & \multirow[b]{2}{*}{ موقع السد } & \multirow[b]{2}{*}{ 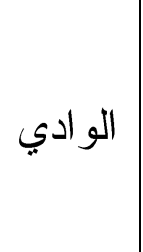 } & \multirow[b]{2}{*}{ اسم السد } & \\
\hline & مُّ الخزن مليون & الارتفاع م & الطول م & & & & ت \\
\hline 1974 & 19 & $1 \leqslant, 0$ & $\leq 9$. & • الكم شمال شرق النخيب & تبال & تبال & 1 \\
\hline $17 r 0$ & 7,9 & 11,0 & iro. & • Vكم جنوب غرب الفلوجة & الغدف & الروضة & r \\
\hline (זי.. & $r, q$ & Yo,0 & $0 .$. & 00 كم جنوب غرب حديثة & حور ان & 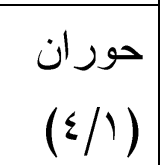 & r \\
\hline r... & $r \wedge, r$ & $r_{1,0}$ & $\varepsilon \ldots$ & . . اكم جنوب غرب حديثة & حوران & $\begin{array}{l}\text { حور } \\
(Y / 1)\end{array}$ & $\varepsilon$ \\
\hline
\end{tabular}

المصدر : عمل الباحثة بالاعتماد على : عبد الوهاب أخضير العبيد ، التلازم بين الخزانات

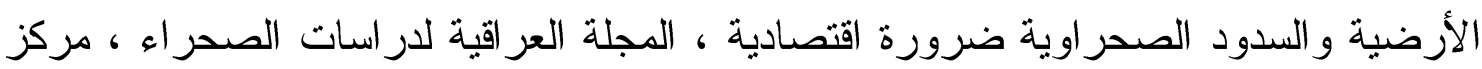

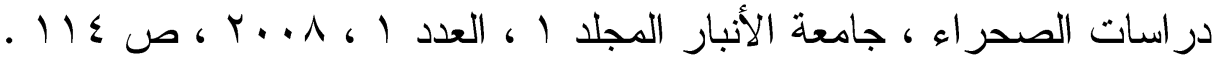

رابعاً: : نقل المياه ( Water transportation ) تعد عملية نقل المياه من الأمور المهمة إذ تحقق هدفين رئيسين وهما: '_ تحقيق الانتظام والتجانس في توزيع الموارد المائية إذ تتم إعادة نقل المياه من الخزانات

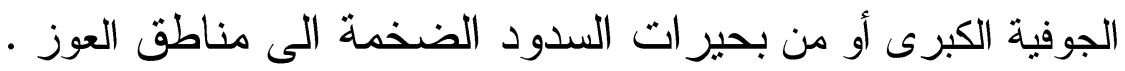
r _ حفظ المياه من الضياع في مناطق الفيض .

ولكي تتم عملية النقل هذه لابد من تو افر أربعة أسس رئيسة وهي (r.): أ_ مصدر مائي مناسب من حيث كميته ونوعيته وتكاليفه . ب_ وسيلة نقل جيدة ورخيصة . جـ_ مناطق تستقيد من المباه المنقولة بدرجة مثلى . 
د__ عدم حدوث أي تأثير ات بيئية على المنطقة المنقول منها الماء و المنقول عليها و إليها ('r)" . نشأت الحاجة الى نقل المباه من مواقع وجودها الى مواقع استعمالاتها منذ القدم ، وقد تعددت أساليب هذا النقل على وفق اختلاف الظروف الطوبوغر افية و المناخية والاقتصادية وقد تم هذا هونا النقل إما بالأنابيب إما بالأقنية المكشوفة وبالصهاريج. تستخدم الأنابيب في بلدان غرب آسيا

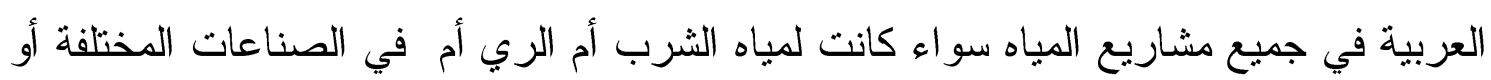
للصرف الصحي ـ تمد خطوط أنابيب المياه عادة ضمن خنادق تحفر على طول مسار الخط ثم يتم ردمها بعد تمديد الخط وتتألف من قطع وصلات ( Joints ) وقطع خاصة فو اصل( (Fittings الأنابيب ويمكن تصنيف أنابيب المياه المستخدمه في المنطقة وفق نوع المادة المصنعة منها إلى ثمانية أصناف و هي (rr) :

- أنابيب البيتون المسلح ( Reinforced concrete ) • Asbests cement ) أنابيب الأترنيبت بـ الأنابيب الفو لاذية ( Steel ) ومنها الفو لاذ الأسود أو المزيبق . ع_ أنابيب الفونت المرن ( Ductile Iron ) • أنابيب البيتون مسبق الإجهاد ( Prestressed concrete ) - ـ أنابيب البولي فينيل كلور ايد ( PVC) • أنابيب البولي ايثيلين ^ـــابيب البوليستر المسلح بالألياف الزجاجية( FRP ) . في مطلع عام 9 . . ب قامت مديرية الزر اعة في محافظة الأثبار بإجر اء مسح للمناطق القابلة

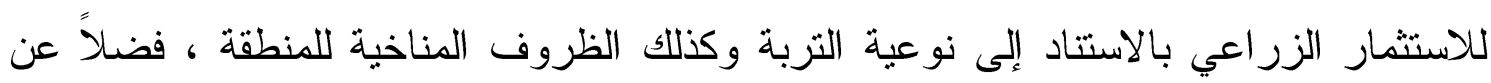
مصدر المياه اللازم لإزواء تللك الأز اضي ، وقد تم ترشيح مناطق للاستثمار الزر اعي بالاعتماد على مياه نهر الفرات ومن هذه المناطق موقعان في قضاء القائم بمساحة ( ... 100 ) دونم الأول بمساحة ( . . . (0 ) دونم ويقع على الجانب الأيسر لنهر الفرات وضمن هضبة الجزيرة ( ديوم الدير و الشعيثي ، كلبان و الطيارة ) تبعد ( 0 كم ) شمال نهر الفرات، أما الموقع 


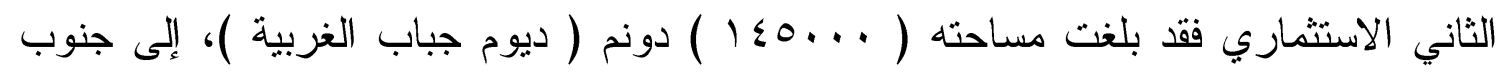

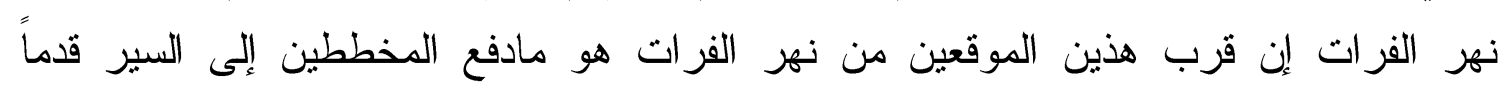

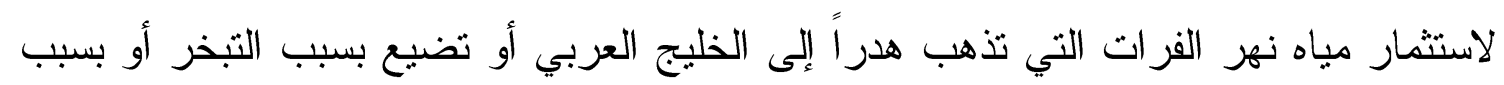

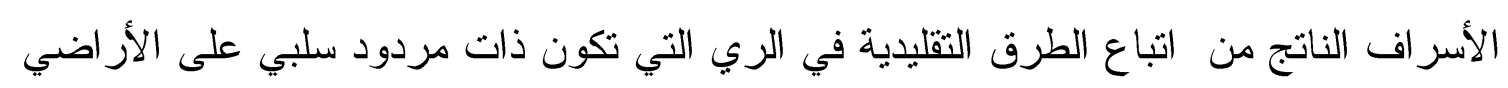

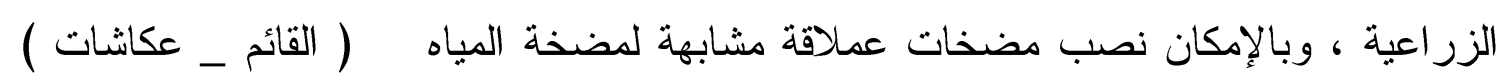

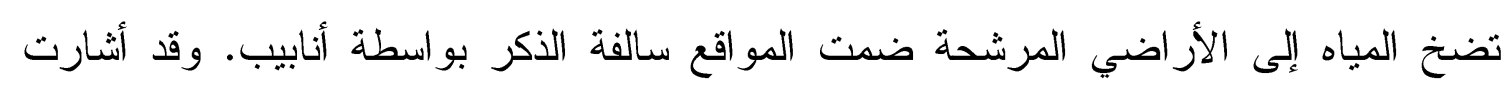

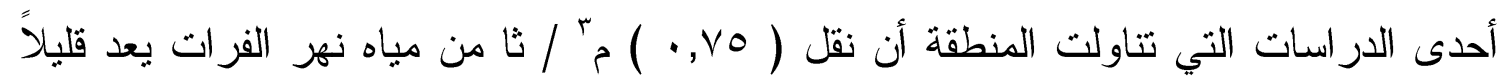

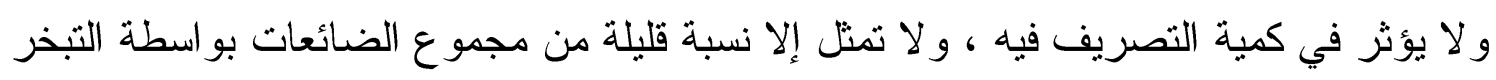

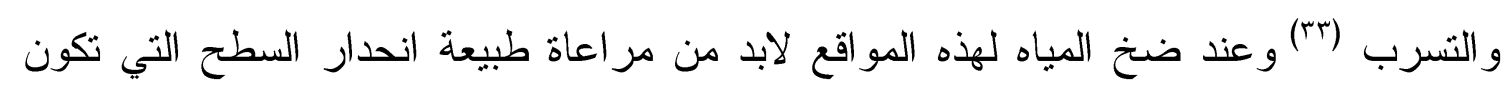
ذات انحدار عام نحو الجنوب والجنوب الشرقي باتجاه نهر الفرات ، مما يسهل عملية إيصال

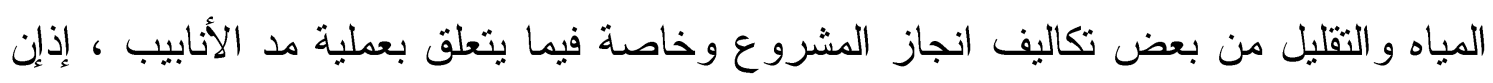

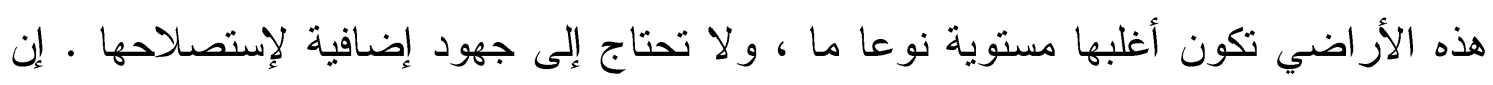

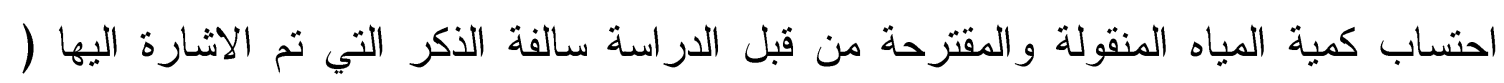

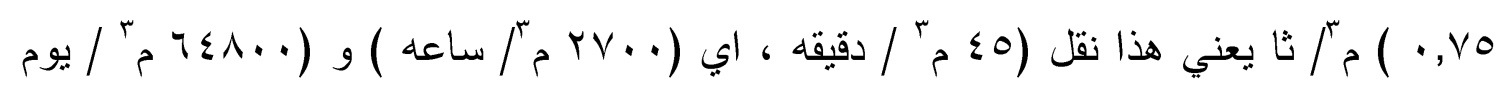

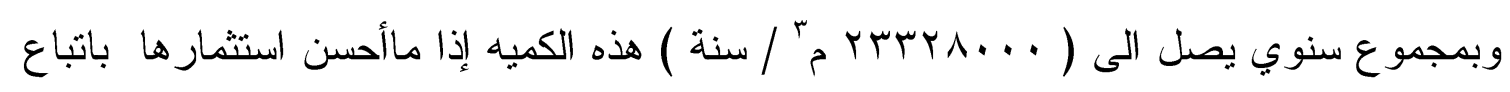

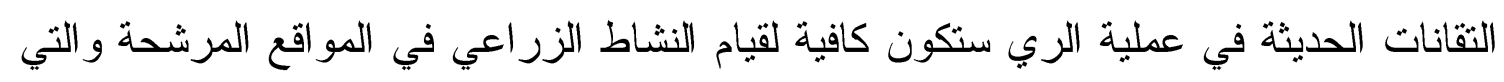

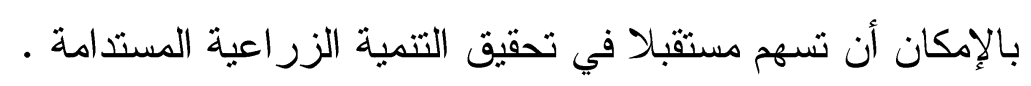

\section{__ زيادة إمدادات الموارد المائية غير التقليدية :}

تتمثل إددادات الموارد المائية غير التقليدية في إعادة استعمال مياه الصرف الصحي

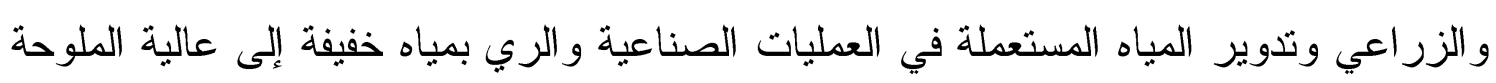

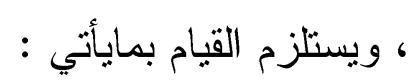

أو لا : إعادة استخدام مياه الصرف الصحي المعالجة في الري تتم في المنازل عن طريق

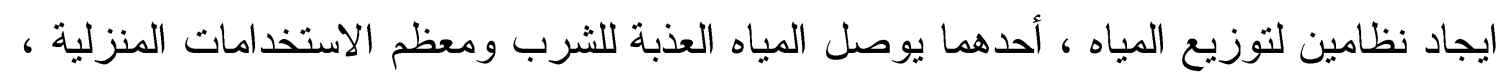

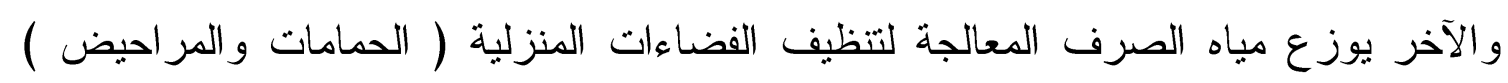
وري المتنز هات وأواسط الطرق وحدائق المساكن ، وقد استخدمت هذه المعالجة في كثير من 
دول العالم المتقدمة والدول العربية ( مصر ، دول الخليج ، سوريا ) وفي العراق توجد محطة

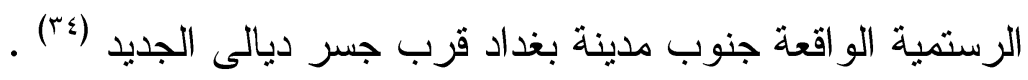

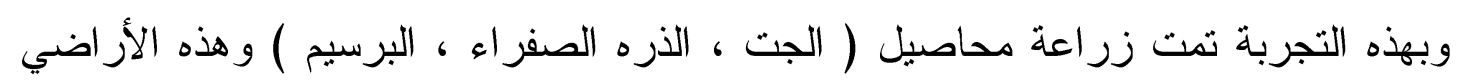

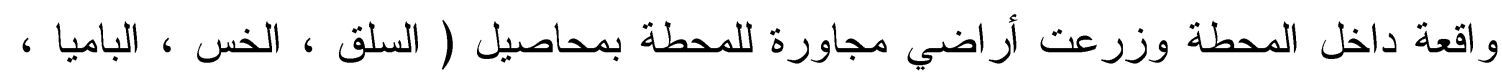

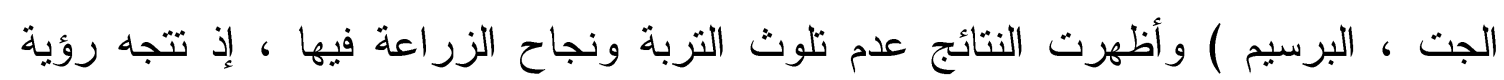

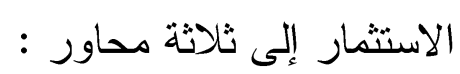

$$
\text { _الأول : استثمار زراعي انتاجي · }
$$

_الثاني : زر اعي تجميلي زر اعة الثجير •

$$
\text { _الثالث : استثمار زر اعي وقائي ( حزام أخضر ) . }
$$

إن هذه التجربة يمكن أن تتدرج ضمن المشاريع الاستثمارية وتتمية الأقاليم في المحافظة ومن خلال إنثاء محطة لمعالجة مياه الصرف الصحي واستخدامها في الأنشطة التي تم ذكرها

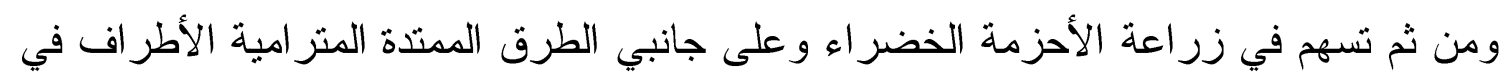
المحافظة واستخدامها في سقي أو اسط الطرق و المتنزهات و الحدائق مما يسهم في تحقيق إدارة الطئ

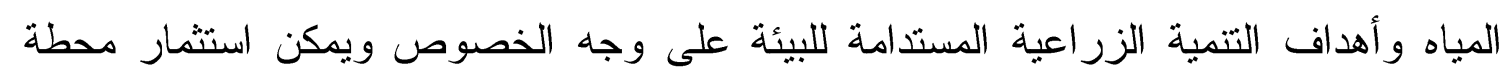

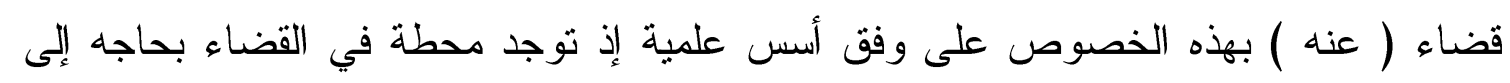
تفعيلها بهذا الاتجاه ، وكان من ضمن خطة نتمية الأقاليم في الدحافظة مشروع تدوير مياه

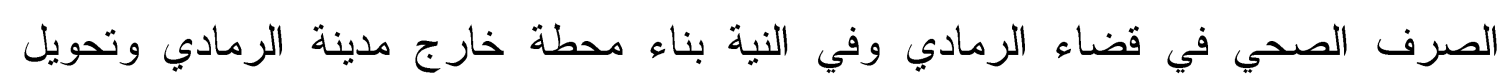

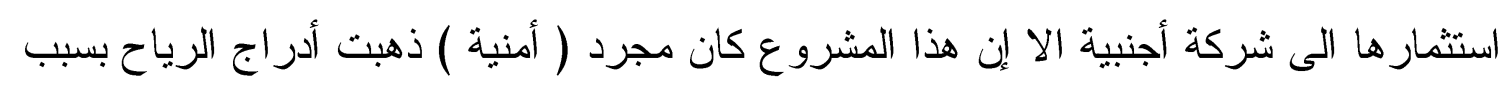

$$
\text { الوضع الأمني. }
$$

تقدر مياه الصرف الزراعي بكميات كبيره عادة ، وهي على الرغم من ملوحتها النسبية

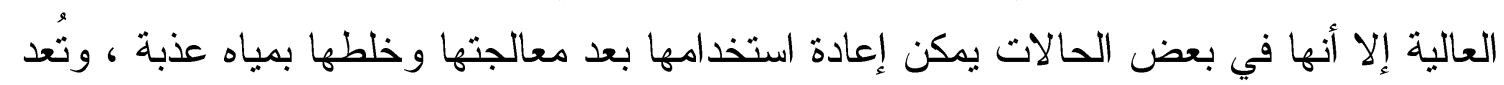

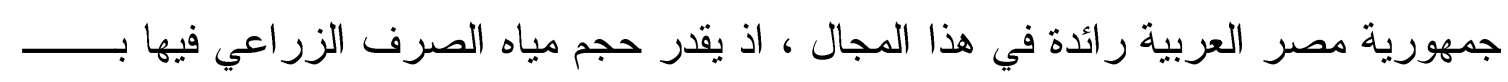

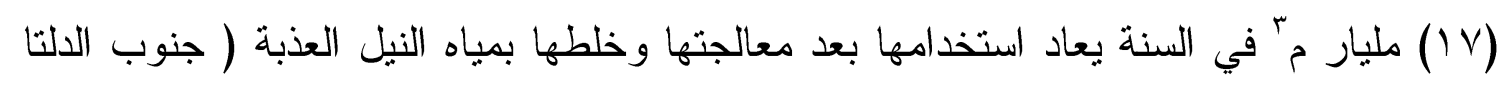

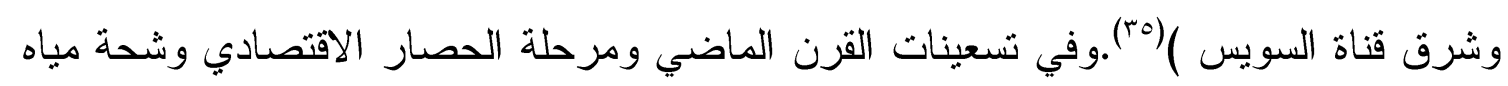

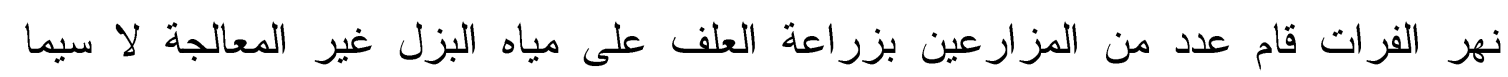


محصولا الجت و الثعير في ريف قضاء الرمادي وقد نجحت الزراعة كون هذه المحاصيل

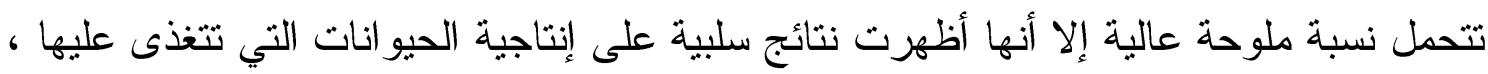

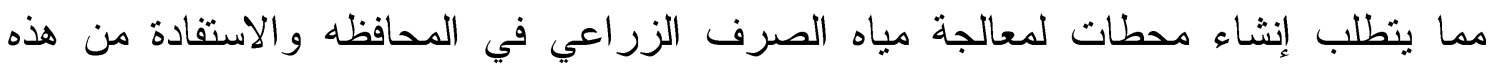

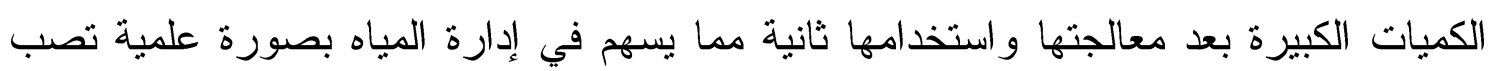

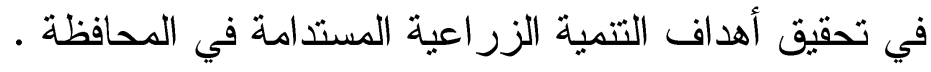

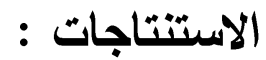

'_ تمتلك محافظة الانبار مو ارد مائية (سطحية وجوفية ) بحاجة إلى إدارة ذات أسس علمية

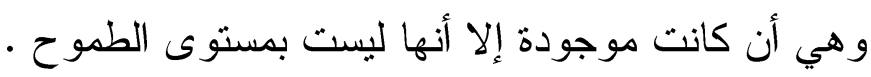

r _ إن توفر الموارد المائية جعل من محافظة الأنبار ذات طابع زراعي مما أسهم في

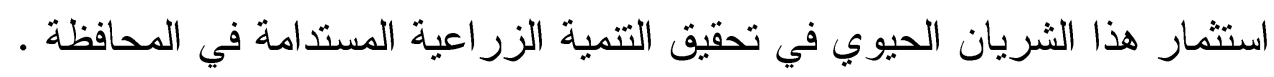

r_ تمتلك المحافظة خزيناً هائلا من المياه الجوفية يسهم في تحقيق التتمية الزراعية

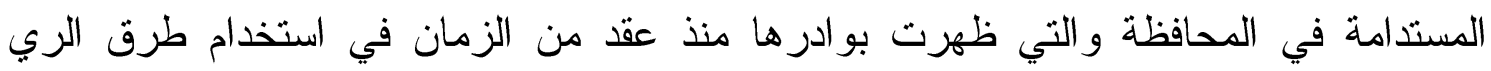

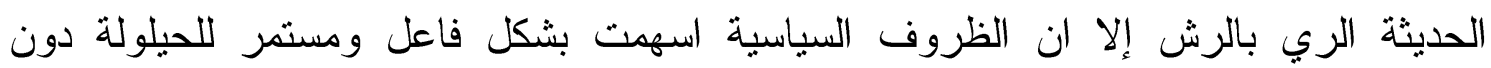

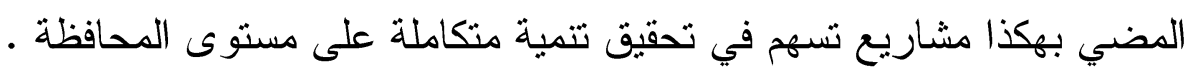

ع_ هناك خطو ات جادة في إدارة المياه ( حصاد الأمطار) ، وذللك ببناء السدود و الخزانات

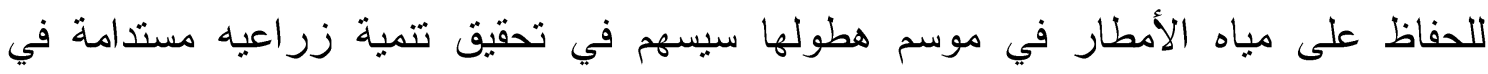
المحافظة ، وإن هذه المشاريع أسهمت بشكل وبآخر في استقرار الرعاة في الهضبة الغربية

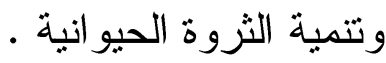

ه_ زيادة حجم السكان و النطور الحضاري أسهم في استهلالك المياه بصورة كبيرة والطلب

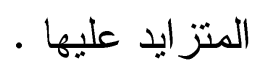

؟_ ان وجود نهر الفرات فضلا عن الخزين الكبير للمياه الجوفية ، سيسهر بشكل فاعل في

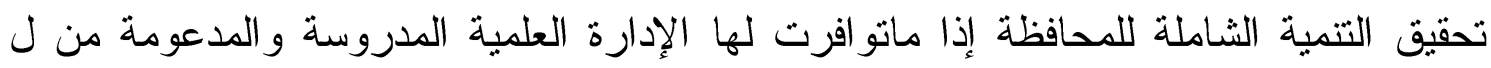
المؤسسات الحكومية ذات العلاقة . 
لـ هناك كمبات كبيرة من مياه الصرف الزراعي تذهب هدرا دون الاستفادة منها ،والتي يمكن الاستفدة منها بعد معالجتها في العملية الزر اعية.

\section{التوصيات :}

1 _ وضع سياسة البحث العلمي الثاملة في الإدارة المائية وتحديد إطر تفعيلها بالجهات ذات

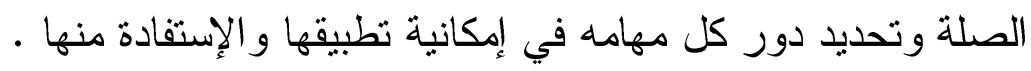

r_ العمل على بناء القدرات و التتمية البشرية في مجال البحث العلمي للإدارة المائية بالتركيز

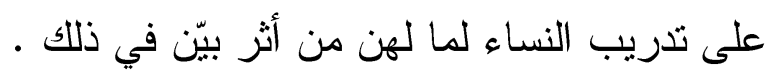

ץ_ أدخال مفردات البحث العلمي للإدارة المائية في المناهج الدراسية ذات الصلة ، وبناء المعرفة في إطار الإدارة الأفضل للموارد المائية .

ع_ دعم الدراسات العلمية لكل الباحثين و المختصين من ذوي الثأن حول مجال ترشيد

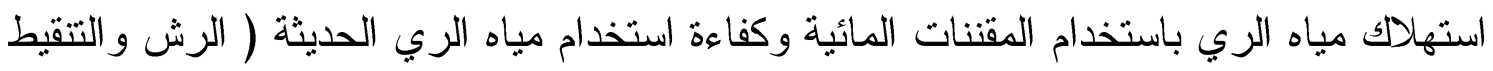
) و أساليب الإدارة المختلفة مباه الري باسنة

○ـ الدعم المستمر لدراسات الوديان والمناطق التي يمكن الإفادة منها في حصاد المياه و العمل على الاستمرار في إدارة مياه الأمطار الأمر الذي يسهر في تحقيق التتمية الزراعية الأبية المستدامة .

؟ ـ سن القو انين لاستثمار المياه الجوفية من لدن القطاع الخاص وتحت إثر اف المؤسسات

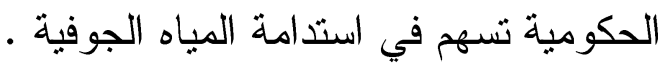

ع _ العمل وبشكل مسؤول على مسنوى رفيع من لدن المؤسسات الحكومية حول المحافظة

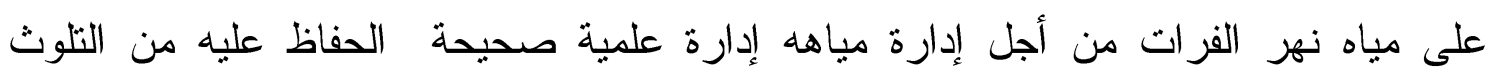
و التجاوزات التي تحدث من قبل المز ارعين على قنوات الدرة مياهه الدرة علي الزر اعية.

^_ من أجل تطوير مجالات البحوث المستقبلية لإدارة المياه تمتينا للمعرفة وتجويدا للإدارة

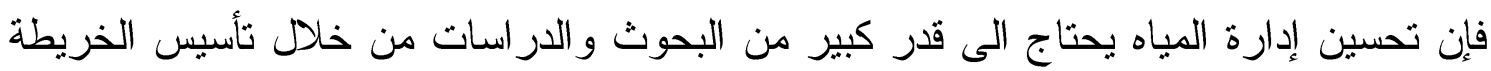

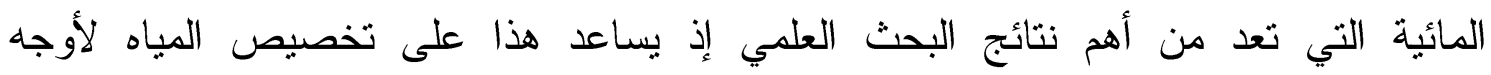
الاستهلاك أو الإستخدام المتنافسة على أسس يتم تحديدها مسبقا . 
9_ العمل على تكوين قاعدة بيانات شاملة للموارد المائية ( الموازنة المائية للخز انات الجوفية ، مصادر المياه المتتوعة ، التلوث و اسبابه ) .

• اــ إثر الك المنظمات غير الحكومية والقطاع الخاص وأجهزة الأعلام في مو اصلة حملة التو عيه العامة لترشيداستخدام المياه و الترويج لتكنولوجيا الري الحديث التي تقلص استخدام المياه 11_ استخدام نظم المعلومات الجغر افية ( GIS ) و الإستشعار عن بعد ؛ لكونها تساعد على المر اقبة و المتابعة المستمره للإزض ومواردها مما يتيح فرص للرصد و المقارنة في مدد زمنية مختلفة تمكن من تحسين إدارة المواردالمائية وتتميتها .

r إ_ ضرورة الالتزام بالمواثثق الدولية و التشريعات القانونية حول المباه الإقليمية لنهر الفرات من لدن دولة المنبع (تركيا) لتخفيف وطأة التجاوزات على الحصة المائية للعراق.

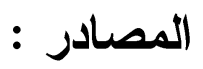

ـ فؤاد سالم معروف، مصادر المياه في الوطن العربي وطرق استدامتها ، مجلة العلوم

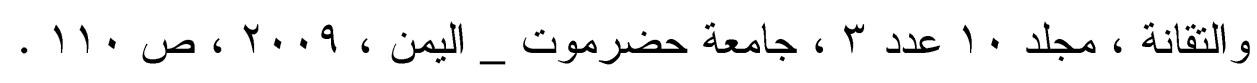
צ _ كتيب الإدارة المتكاملة للموارد المائية في أحواض الأنهار و البحيرات وطبقات المياه http.www.inb-news.org.

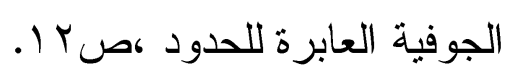

http//www.usaid.gov/our-work/environment/water/what $\cdot 3$ ع_المنظمة العربية للتمية الزر اعية في الوطن العربي،دراسة وتطوير أساليب استرداد تكلفة

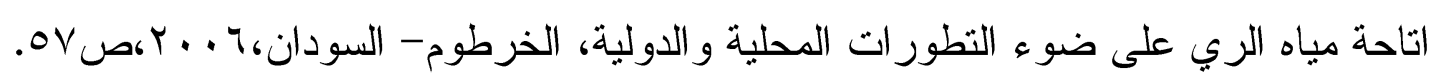
0_ علي أديب محمد ، أحمد آدم إير اهيم ، عصام عبد الماجد ، عمر محمد العوض ، مستقبل البحث العلمي في مجال الإدارة المائية للإغراض الزر إعية ، مركز البحوث والاستشارات

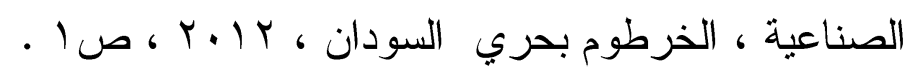

؟ ـ محمود الإشرم ، التتوع الحيوي و التتمية المستدامة و الغذاء ( عالميا وعربيا ) ، مركز

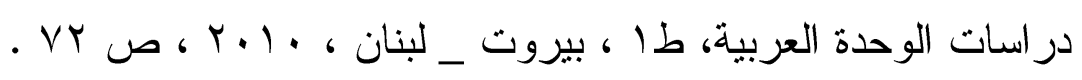


Y_ المنظمة العربية للتنمية الزر اعية ، تعزيز إستخدام تقانات حصاد المباه في الدول العربية

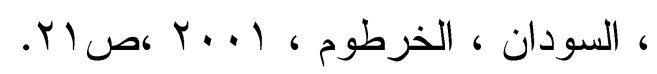

^ــ وزارة التخطيط ،الجهاز المركزي للأحصاء،مديرية الإحصاء الزر اعي،استخدام الموارد

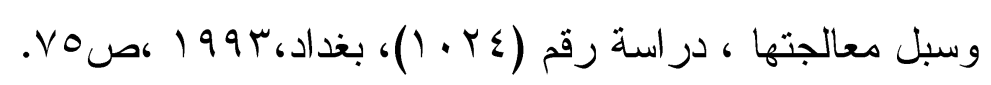

9_المنظمة العربية للتنمية الزراعية ،التقرير السنوي للتنمية الزر اعية في الوطن العربي

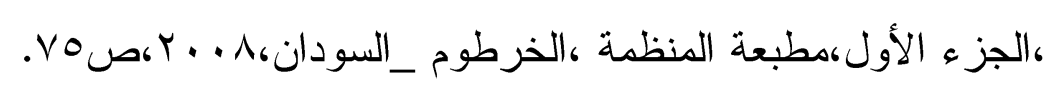

• اـ باسم حازم البدري ، المشكلات المتعلقة بالأمن المائي العربي وحماية البيئة،الوضع

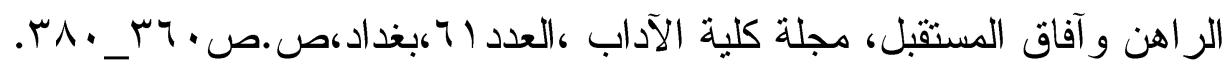
ا'_ باسم حازم البدري،أثز شحة الموارد المائية على الزراعة المروية في العراق،مجلة

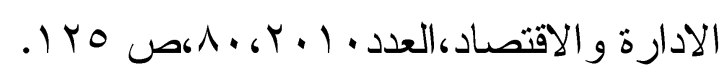

r _ محمد دلف أحمد الدليمي ، فواز أحمد موسى ، و ادي نهر الفرات في سوريا و العراق ،

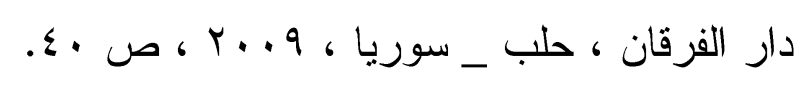
* المنشاطئة ، و هي الدول التي تقع أراضيها أو إجزاء منها في حوض تغذية النهر مع الدول التي يمر بأر اضيها _ للمزيد ينظر ، وليد رضوان ، مشكلة المياه بين العراق وسوريا وتركيا ،

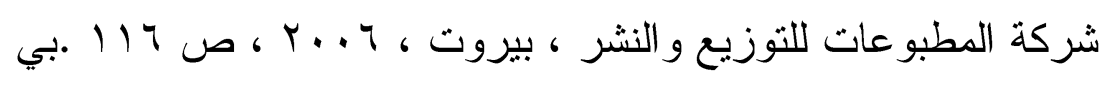

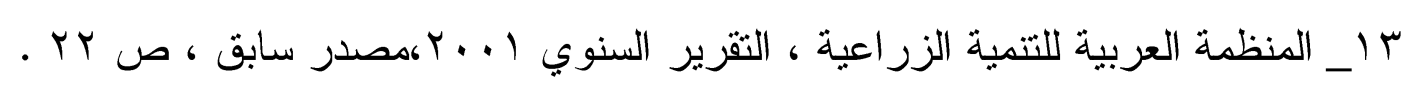
ع ا_ محمد دلف أحمد الدليمي ، نسرين عواد الجصاني ، إدارة الموارد المائية ودورها في معالجة أزمة المياه في الإقاليم الجافة ( الإقليم الصحر اوي في العراق ـ حالة در اسة ) ، المجلة الدولية للبيئة و المياه و المنظمة الأورعربية لاتجاهات البيئة و المياه ، الصحر اء ، مجلد ا الاهية ، العدد

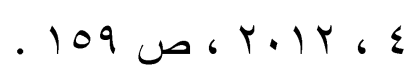

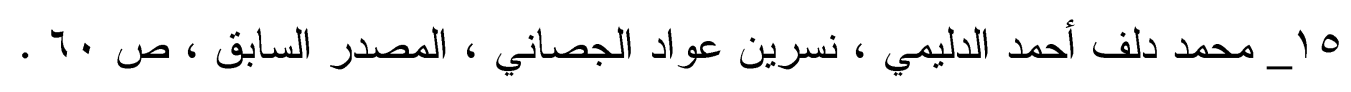
7 ا - محمد دلف أحمد الاليمي ، فواز أحمد موسى ، مصدر سابق ، ص 110 


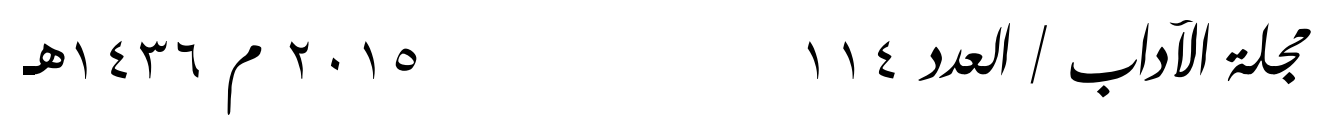

صؤ_ IV اد سالم معروف، مصادر المباه في الوطن العربي وطرق استدامتها ، مصدر سابق،

ص.

11 ـ محمد دلف أحمد الدليمي ، فواز أحمد موسى ، مصدر سابق ، ص 110 ـ 11

19_ المنظمة العربية للتمية الزراعية في الوطن العربي ، تقانات حصاد المياه ،مصدر

سابق ، ص 17 . 17

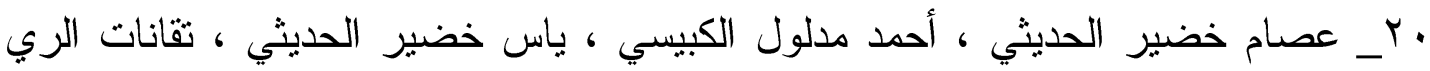

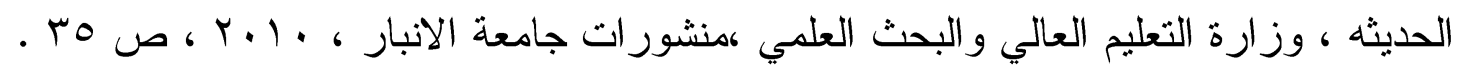

ابr_المنظمة العربية للتنمية الزراعية في الوطن العربي ،ثقانات حصاد المباه، مصدر

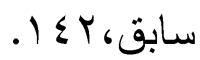

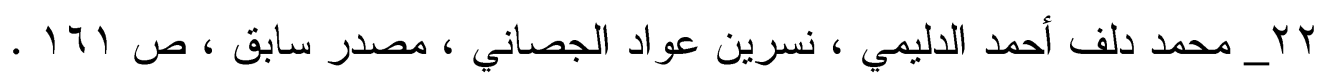

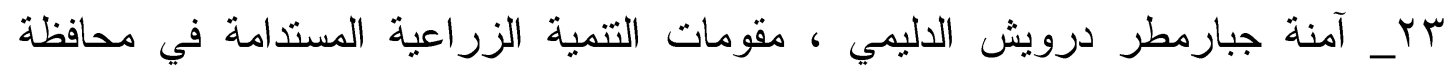

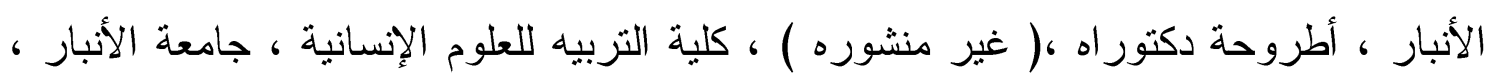

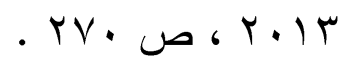

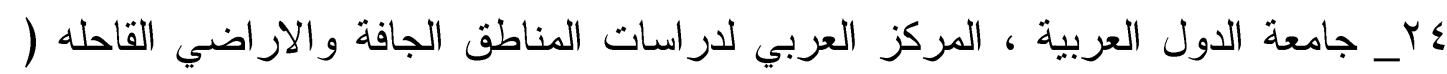

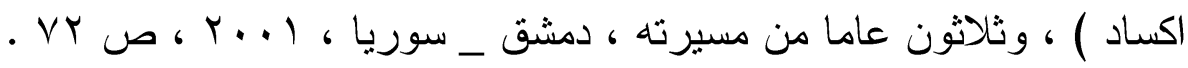

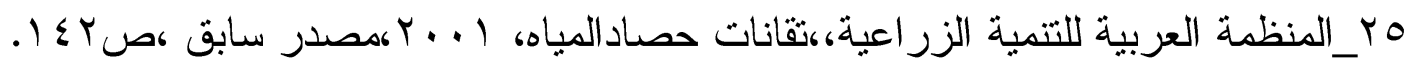

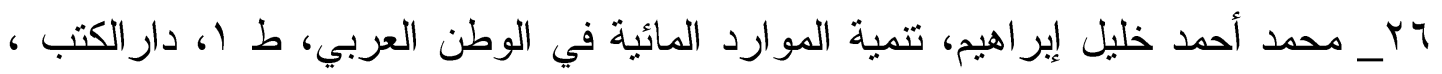

القاهره ،0... Y ص .9 .9 .

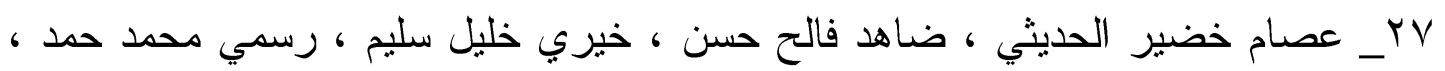

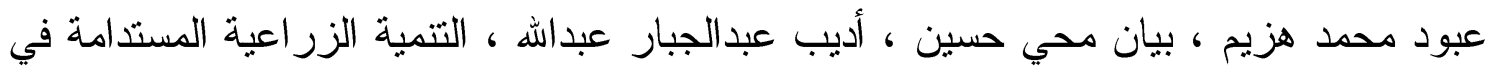

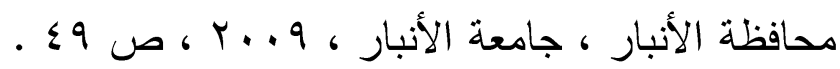




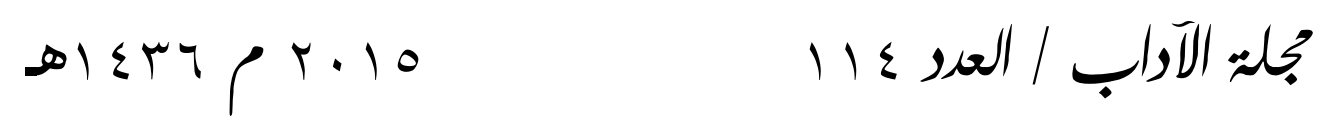

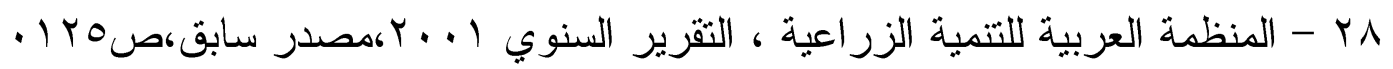

وץ_ ينظر نصير الإنصاري ، حوض نهر الفرات و الأمن الغذائي الإستراتيجي للعراق ،

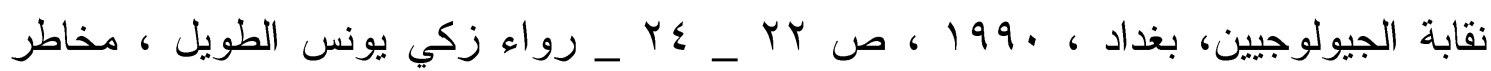

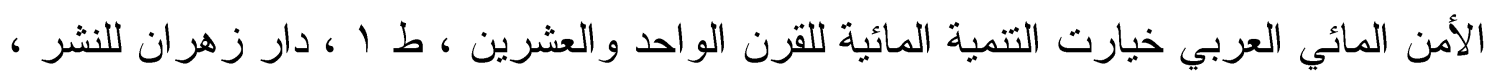

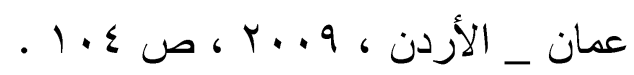

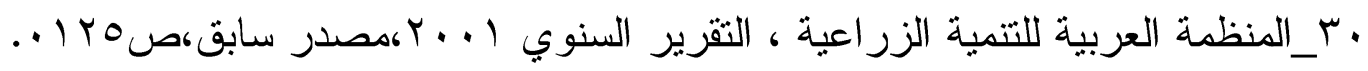

اب_ حسن محمد الجديدي ، البدائل المطروحة لمو اجهة تتاقص المياه الجوفيه ، ط ا ، دار

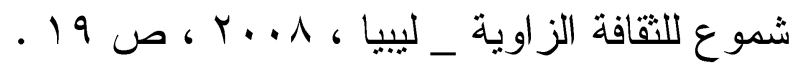

r r _ــ المركز العربي لدراسات المناطق الجافة و الار اضي القاحلة( اكساد )، التقرير الفني عن

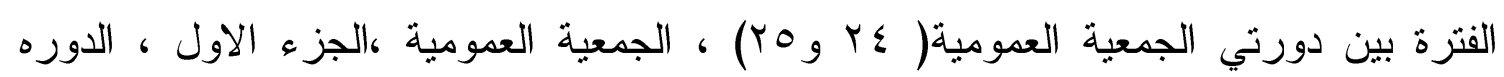

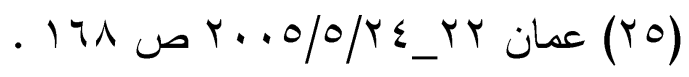

سبـ أنور مهدي صالح ، مقترح تتمية إقليم شامية حصيبة الغربية انطلاقة لأعمار الصحر اء

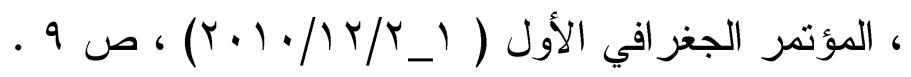

ع ــ آلاء ذاكر عذاب عبيد ، استثمار المياه العادمة والمعالجة في الزراعه في محطة الرستميه ، رسالة ماجستير ، ( غير منشوره ) ، كلية الآداب ، جامعة بغداد ، 11 • ، ، ص . |N|

هب_ عصام خضير الحديثي وآخرون ، تقانات الري الحديثة، مصدر سابق ، ص رسץ . 
The Water management and it role in agricultural sustainable development in Anbar Governorate

\author{
D.Amna J. Al.Duleimi \\ University of Anbar _ College of Education for women, Dept. of \\ Geography
}

\begin{abstract}
: _
Iraq have climate condition dry and sub dray, moreover evergehigh Evaporation and quantity limited, Euphrates river come from out Borders more over null Artevies feed it inside the Provence from these water resources of renewal are Basic of Economical and social development for country or Provence, there for study aim to disclose role of water management in sustainable of Agricultural, during arrangement of inrestment and good using for water resources of available in availability and whole need to it multisctorsas agricultural, in dustrial or houses during follow water management contribute in process of agricultural sustainable development in Governorate .
\end{abstract}

